\title{
Dual role of ER stress in response to metabolic co-targeting and radiosensitivity in head and neck cancer cells
}

\author{
Oleg Chen ${ }^{1,2} \cdot$ Friederike Manig $^{1,3} \cdot$ Loreen Lehmann $^{1} \cdot$ Nagwa Sorour $^{1} \cdot$ Steffen Löck ${ }^{1,4,5,6} \cdot$ Zhanru Yu $^{7}$. \\ Anna Dubrovska ${ }^{1,4,5,8} \cdot$ Michael Baumann $^{1,5} \cdot$ Benedikt M. Kessler ${ }^{7} \cdot$ Oleh Stasyk $^{2} \cdot$ Leoni A. Kunz-Schughart ${ }^{1,9}$ (i)
}

Received: 25 May 2020 / Revised: 19 October 2020 / Accepted: 4 November 2020 / Published online: 23 November 2020

(c) The Author(s) 2020

\begin{abstract}
Arginine deprivation therapy (ADT) is a new metabolic targeting approach with high therapeutic potential for various solid cancers. Combination of ADT with low doses of the natural arginine analog canavanine effectively sensitizes malignant cells to irradiation. However, the molecular mechanisms determining the sensitivity of intrinsically non-auxotrophic cancers to arginine deficiency are still poorly understood. We here show for the first time that arginine deficiency is accompanied by global metabolic changes and protein/membrane breakdown, and results in the induction of specific, more or less pronounced (severe vs. mild) ER stress responses in head and neck squamous cell carcinoma (HNSCC) cells that differ in their intrinsic ADT sensitivity. Combination of ADT with canavanine triggered catastrophic ER stress via the eIF2 $\alpha$-ATF4(GADD34)CHOP pathway, thereby inducing apoptosis; the same signaling arm was irrelevant in ADT-related radiosensitization. The particular strong supra-additive effect of ADT, canavanine and irradiation in both intrinsically more and less sensitive cancer cells supports the rational of ER stress pathways as novel target for improving multi-modal metabolic anti-cancer therapy.
\end{abstract}

Keywords Metabolic targeting · Arginine-deprivation therapy $\cdot$ ER stress $\cdot$ Canavanine $\cdot$ Radiosensitization $\cdot$ Head and neck squamous carcinoma $\cdot 3$-D culture

Abbreviations
ADT
Akt
Arg
ASS
ATF3
ATF4

Electronic supplementary material The online version of this article (https://doi.org/10.1007/s00018-020-03704-7) contains supplementary material, which is available to authorized users.

Leoni A. Kunz-Schughart

leoni.kunz-schughart@oncoray.de

1 OncoRay, National Center for Radiation Research in Oncology, Faculty of Medicine and University Hospital Carl Gustav Carus, TU Dresden and Helmholtz-Zentrum Dresden-Rossendorf, Fetscherstraße 74, 01307 Dresden, Germany

2 Department of Cell Signaling, Institute of Cell Biology, National Academy of Sciences of Ukraine, Lviv, Ukraine

3 Chair of Food Chemistry, TU Dresden, Dresden, Germany

4 German Cancer Consortium (DKTK), Partner Site Dresden, Germany
ATF6

$\operatorname{Atg} 12$

Bax

Bcl-2

Bim

Cav

CHOP

Cit

comb-ADT
Activating transcription factor 6 Autophagy related 12 Bcl-2-associated X protein B-cell lymphoma 2

Bcl-2-like protein 11

Canavanine

C/EBP homologous protein

Citrulline

Arginine deprivation therapy combined with canavanine
5 German Cancer Research Center (DKFZ), Heidelberg, Germany

6 Department of Radiation Oncology, University Hospital Carl Gustav Carus, Dresden, Germany

7 Target Discovery Institute, Nuffield Department of Medicine, University of Oxford, Oxford, UK

8 Institute of Radiooncology, Helmholtz-Zentrum Dresden-Rossendorf, Dresden, Germany

9 National Center for Tumor Diseases (NCT), Partner Site Dresden, Germany 


\begin{tabular}{|c|c|}
\hline CPD & $\begin{array}{l}\text { Cumulative population } \\
\text { doublings }\end{array}$ \\
\hline cPARP & $\begin{array}{l}\text { Cleved poly(ADP-ribose) } \\
\text { polymerase }\end{array}$ \\
\hline DMEM & $\begin{array}{l}\text { Dulbecco's modified eagle } \\
\text { medium }\end{array}$ \\
\hline DMSO & Dimethyl sulfoxide \\
\hline DRF & Dose reduction factor \\
\hline EDTA & Ethylenediaminetetraacetic acid \\
\hline $\operatorname{eIF} 2 \alpha$ & $\begin{array}{l}\text { Eukaryotic translation initiation } \\
\text { factor } 2 \alpha\end{array}$ \\
\hline ER stress & Endoplasmic reticulum stress \\
\hline Erk1/2 & $\begin{array}{l}\text { Extracellular signal-regulated } \\
\text { kinase } 1 / 2\end{array}$ \\
\hline ESI & Electrospray ionization \\
\hline FCS & Fetal calf serum \\
\hline GADD34 (PPP1R15A) & $\begin{array}{l}\text { Growth arrest and DNA dam- } \\
\text { age-inducible protein }\end{array}$ \\
\hline GAPDH & $\begin{array}{l}\text { Glyceraldehyde-3-phosphate } \\
\text { dehydrogenase }\end{array}$ \\
\hline GCxGC-Qms & $\begin{array}{l}\text { High-speed scan single quadru- } \\
\text { pole mass spectrometry }\end{array}$ \\
\hline Grp78 (HSPA5) & $\begin{array}{l}78-\mathrm{KDa} \text { glucose-regulated } \\
\text { protein }\end{array}$ \\
\hline HEPES & $\begin{array}{l}\text { 4-(2-Hydroxyethyl)-1-pipera- } \\
\text { zineethanesulfonic acid }\end{array}$ \\
\hline HNSCC & $\begin{array}{l}\text { Head and neck squamous cell } \\
\text { carcinoma }\end{array}$ \\
\hline HPV & Papillomavirus \\
\hline $\operatorname{IRE} 1 \alpha$ & Inositol-requiring enzyme $1 \alpha$ \\
\hline LC3-II & $\begin{array}{l}\text { Microtubule-associated protein } \\
\text { 1A/1B-light chain } 3\end{array}$ \\
\hline LC-MS & $\begin{array}{l}\text { Liquid chromatography mass } \\
\text { spectrometry }\end{array}$ \\
\hline MAPK & Mitogen-activated protein kinase \\
\hline mono-ADT & $\begin{array}{l}\text { Arginine deprivation } \\
\text { mono-therapy }\end{array}$ \\
\hline mTOR & Mammalian target of rapamycin \\
\hline PBS & Phosphate-buffered saline \\
\hline PERK & $\begin{array}{l}\text { Protein kinase } \mathrm{R} \text { (PKR)-like } \\
\text { endoplasmic reticulum kinase }\end{array}$ \\
\hline PP1 & Protein phosphatase 1 \\
\hline q-PCR & $\begin{array}{l}\text { Real-time quantitative polymer- } \\
\text { ase chain reaction }\end{array}$ \\
\hline rhARG & Recombinant human arginase \\
\hline RT-PCR & $\begin{array}{l}\text { Reverse transcription polymer- } \\
\text { ase chain reaction }\end{array}$ \\
\hline Sal & Salubrinal \\
\hline $\mathrm{SCD}_{50}$ & Spheroid control dose 50 \\
\hline $\mathrm{SCP}$ & Spheroid control probability \\
\hline SFD & Surviving fraction dose \\
\hline siRNA & Small interfering RNA \\
\hline SQSTM1 (p62) & Sequestosome-1 \\
\hline
\end{tabular}

SUMO

$\mathrm{TCD}_{50}$

TCGA

UHPLC

XBP1

\section{Introduction}

During the past decade, significant progress has been accomplished in the development of enzymotherapeutic arginine deprivation therapy (ADT) for anticancer treatment. Systemic withdrawal of arginine (Arg) from the patients' blood stream can be achieved using one of two types of Argdegrading enzymes, recombinant human arginase (rhARG) or bacterial arginine deiminase (ADI). Both enzymes are available in pegylated form and have entered pre-clinical and clinical phase I/II trials, in particular for the treatment of putative Arg-auxotrophic tumors [1-6]. The proposed cancer cells targeted by ADT are incapable of Arg de novo synthesis mainly due to deficiency in argininosuccinate synthetase (ASS), the rate-limiting enzyme of citrulline (Cit) to Arg conversion $[3,7,8]$.

Recently, we demonstrated a strong synergistic effect when ADT was combined with low concentrations of Cav [9-13]. The natural Arg analog Canavanine (Cav) can effectively compete with Arg for arginyl tRNA synthase and incorporates into cellular proteins, thereby causing conformational changes and impairing enzymatic activities and functions [14]. ADT was also found to efficiently sensitize even non-auxotrophic colorectal cancer and glioblastoma cells to irradiation $[10,13,15]$. However, the molecular mechanism(s) underlying the cancer cells' reprogramming to Arg deficiency and its link to radiosensitization are virtually unknown.

Our previous studies indicate that cancer cells in the absence of exogenous Arg rapidly deplete their internal Arg pools, repress global protein translation by activation of the GCN2-mediated pathway, and inhibit mTOR signaling in both 2-D and 3-D models [16]. Prolonged ADT was also shown to induce endoplasmic reticulum (ER) stress responses [11]. Activated ER stress pathways primarily have pro-survival functions to resolve and overcome the stress conditions. In case of massive or unresolved ER stress, the pathways switch to cause apoptotic cell death [17]. It remains unclear, how and when this switch is flicked in cancer cells under Arg-deprived conditions in mono- and combinatorial treatment settings, and whether interference with selective ER stress responses could further improve ADT outcome. 
In the present study, we for the first time examined the mechanistic role of ER stress in radiosensitization and apoptosis induction upon mono-ADT (Arg deprivation mono-therapy) and comb-ADT (Arg deprivation therapy combined with Cav) in head and neck squamous cell carcinoma (HNSCC) models. HNSCC comprise a heterogeneous group of cancer subtypes accounting for $>750,000$ cases and $\sim 350,000$ disease-related deaths worldwide each year [18]. A minor subgroup of HNSCC causally relates to HPV infection; these $\mathrm{HPV}^{+} \mathrm{HNSCC}$ show a specific molecular pathogenesis with favorable prognosis and were intentionally excluded from our investigation. Most HNSCC patients $(\sim 70 \%)$ are first diagnosed with large primary cancers and/or at locoregionally advanced stages. The standard-of-care treatment in those cases is multimodal and includes radio(chemo)therapy. However, the survival outcome of the patients remains modest (5-year survival $25-49 \%$ depending on location). Combining mono-ADT or comb-ADT with ionizing radiation could thus be a promising alternative, individualized treatment strategy. With a systematic study design, we identified responder and non-responder HNSCC models and found a dualistic role of selectively activated ER stress pathways in cell death and radiosensitization. New fundamental insight in the role of triggered ER stress response upon mono- and comb-ADT is given.

\section{Materials and methods}

\section{HNSCC cell lines}

Nine established human HNSCC lines were used in this study. The origin of the cell lines in our laboratory has been highlighted earlier in $[19,20]$. In brief, UT-SCC-5, UTSCC-8, UT-SCC-14 and UT-SCC-15 cells were kindly provided by Prof. Reidar Grenman MD PhD, from the University of Turku (Finland); HSC-4 and SAS cells were obtained from the HSRRB (Japan), XF354 cells from the German Cancer Research Center (DKFZ, Germany), and Cal-33 cells from the German Collection of Microorganisms and Cell Cultures (DSMZ, Germany). The FaDu cells applied herein represent a subline of FaDu-ATCC HTB-43 as pointed out earlier [21]. All cell lines were routinely tested free of mycoplasms using a PCR Mycoplasma Kit (AppliChem). Authentication and purity of the HNSCC cell line panel were verified prior to use via multiplex PCR kits, i.e. Mentype ${ }^{\circledR}$ Nonaplex ${ }^{\mathrm{QS}}$ Twin (Biotype) and the PowerPlex ${ }^{\circledR} 16$ System (Promega) at the Institute of Legal Medicine (TU Dresden, Germany). Cultures were routinely grown from the validated frozen stocks for $\geq 2$ to $\leq 20$ passages $(<120 \mathrm{CPD}$-cumulative population doublings).

\section{Monolayer and spheroid routine culturing}

All cells were cultured as monolayers in standard Dulbecco's Modified Eagle Medium (DMEM) with L-glutamine, D-glucose $(1 \mathrm{~g} / \mathrm{L})$ and $25 \mathrm{mM}$ HEPES supplemented with $10 \%$ heat-inactivated fetal calf serum (FCS) and $1 \%$ penicil$\mathrm{lin} /$ streptomycin $(10,000 \mathrm{U} / \mathrm{mL} / 10 \mathrm{mg} / \mathrm{mL})$. Exponentially growing cultures were kept at $37^{\circ} \mathrm{C}$ in a humidified atmosphere with $8 \% \mathrm{CO}_{2}$ in air. Exponential monolayer cultures were enzymatically dissociated using a solution of $0.05 \%$ trypsin and $0.02 \%$ in phosphate-buffered saline (PBS) to obtain single cell suspensions for passaging and experimental setup. All media, media supplements, solutions and buffers for both routine culturing and therapeutic intervention were from PAN-Biotech if not stated otherwise. A CASY ${ }^{\circledR}$ TTC device (Roche Innovatis) was applied for cell counting, cell volume analysis and culture quality assessment.

Spheroids were cultured in conventional liquid overlay as described previously [22]. In brief, 1000 SAS cells or 2500-3500 FaDu cells derived from exponentially growing monolayer cultures were seeded in $200 \mu \mathrm{L}$ of regular DMEM per well in 96-well plates coated with $1.5 \%$ agarose (Sigma-Aldrich). After 4 days of initiation, all spheroids should have reached a standard diameter of $370-400 \mu \mathrm{m}$ for both cell lines. Spheroids were fed every $48-72 \mathrm{~h}$ by $50 \%$ medium renewal independent of the type of treatment. Spheroid integrity and growth kinetics were routinely monitored by semi-automated measurement of spheroid diameters (and volumes) from phase contrast images taken with an adequately equipped Axiovert200M microscope (Carl Zeiss MicroImaging) as detailed in [15, 22].

\section{Therapy implementation: mono-ADT, comb-ADT, irradiation}

Mono-ADT in culture was mimicked in vitro using formulated Arg-free DMEM. The appropriate control medium was generated by supplementation of Arg-free DMEM with Arg to a final concentration according to standard DMEM. Media were supplemented with $10 \%$ dialysed FCS, depleted of molecules below $10 \mathrm{kDa}$ (i.e. amino acids). For practical reasons, mono-ADT was achieved for selected experimental series (i.e. metabolomics study) by exposure to $2 \mathrm{U} / \mathrm{mL}$ yeast-derived recombinant human arginase I (rhARG; provided by the Institute of Cell Biology, NASU, Lviv, Ukraine) in the presence of physiological Cit according to a previous study $[15,16]$. Successful deprivation of intracellular Arg was monitored by high-resolution mass spectrometry as described later (Fig. S5A).

Comb-ADT in culture was achieved by formulated Arg-free DMEM supplemented with $0.01-0.1 \mathrm{mM}$ of the natural arginine analog Cav (Sigma-Aldrich). In some experiments, the precursor of Arg-Cit was added at a 
physiological concentration of $0.04 \mathrm{mM}$. ER stress modulators such as $0.02 \mathrm{mM}$ salubrinal (Sal; Sigma-Aldrich) or 2\% dimethyl sulfoxide (DMSO; Sigma-Aldrich) were applied $1 \mathrm{~h}$ before and throughout exposure to mono- or comb-ADT. A $4 \mathrm{mM}$ stock solution of Sal in DMSO was prepared, stored at $-20{ }^{\circ} \mathrm{C}$ and always freshly diluted in medium prior to use; accordingly, control cells were exposed to medium containing $0.5 \%$ of DMSO.

Irradiation was performed at room temperature with an $\mathrm{X}$-ray approach $(200 \mathrm{kV}, 0.5 \mathrm{~mm} \mathrm{Cu}$ filter, Yxlon Y.TU 320 , Yxlon.international) and single doses of 0-12 Gy for 2-D and 0-30 Gy for 3-D cultures (dose rate $~ 1.3 \mathrm{~Gy} /$ $\min )$.

\section{2-D and 3-D growth and re-growth experiments}

Monolayer cells were seeded at a density of $1 \times 10^{4}$ cells per well in 6-well culture dishes. Cells were allowed to attach overnight, washed with PBS, and then medium was exchanged to provide an Arg-free environment. At defined time intervals, cell numbers in at least three wells were measured using the CASY ${ }^{\circledR}$ TTC analyzer after cell dissociation. To evaluate growth restoration capability upon ADT, Arg-free medium was exchanged in a sufficient number of wells by standard DMEM containing $0.4 \mathrm{mM} \mathrm{Arg}$ and membrane-intact cells were counted 3 days later.

Spheroids with a diameter of $370-400 \mu \mathrm{m}$ were obtained as described above, collected, carefully washed with PBS and individually transferred into new agarosecoated 96-well plates prepared from serum-free, Arg-free medium for controlled exposure to Arg-free conditions with or without $0.04 \mathrm{mM}$ Cit and $0.1 \mathrm{mM} \mathrm{Cav}$ (SigmaAldrich). After defined treatment intervals, spheroids were re-transferred into standard supplemented DMEM and monitored for at least 10-15 more days. A minimum of 30 spheroids were analyzed per treatment arm. Growth delay $t_{\mathrm{SGD}}$ represents the different time intervals of treated versus control spheroids to reach 5-times the starting volume $\left(5 \times V_{0}\right)$, with the starting volume $\left(V_{0}\right)$ being defined as the spheroid volume directly before the onset of treatment, respectively. To determine spheroid growth delay, the time of each spheroid to reach $5 \times V_{0}$ was evaluated. For this purpose, the monitoring time points closest to the individual $5 \times V_{0}$ were identified, and regression analyses through the logarithm of the corresponding spheroid volumes were used to estimate the individual time to reach $5 \times V_{0}$. The $t_{\mathrm{SGD}}$ values were then calculated by subtracting the average time of control spheroids to reach their $5 \times V_{0}$ from the individual time periods required by the treated spheroids and are documented as means \pm SD.

\section{2-D clonogenic survival assay}

Exponentially growing HNSCC cells were dissociated, single-cell suspensions were prepared in standard DMEM and seeded cell line-dependent at low (between 100 and 10,000) in 6-well plates to allow counting of single-cell colonies. After overnight incubation to allow cell adherence, supernatants were removed, cells were carefully washed with PBS and specific media for mono- or comb-ADT were added $(2 \mathrm{~mL} /$ well $)$ as described in "Therapy Implementation". Single-dose irradiation was performed after $24 \mathrm{~h}$ of treatment followed by medium exchange to restore Arg-rich conditions for a period of $\geq 5-6$ cell divisions estimated from the cell line-specific doubling times of the respective controls. Hence, the culturing time ranged between 8 and 14 days for the cell line panel except for UT-SCC- 8 cells which required a period of 20 days due to their low growth rate under the same conditions. An additional, careful washing step with PBS was performed after irradiation in experimental series with comb-ADT in the absence and presence of ER stress modulators. Control cells and wells, respectively, under + Arg conditions were also irradiated after attachment to exclude effects due to cell divisions before irradiation. After the defined, cell-line specific growth intervals, cells were fixed, stained and colonies with $>50$ cells were manually counted at low magnification to calculate plating efficiencies (PE) and survival fractions (SF) relative to controls. Cell survival curves were fitted by employing the linearquadratic model as described in [15].

\section{Spheroid control probability assay}

Spheroids with standard size were exposed to mono-ADT or comb-ADT for 1 day as described in "Therapy implementation", and were then irradiated with 0-30 Gy single-dose $\mathrm{X}$-ray. Subsequently, treatment was terminated by exchanging and supplementing the Arg-free media to restore Argrich conditions. Control spheroids were irradiated at day 4 in culture to minimize growth effects, i.e. spheroids under mono- and comb-ADT did not grow and showed the same size and volume range on day 5 before irradiation as control spheroids in standard DMEM at day 4 in culture. Spheroid feeding after treatment over the entire post-treatment monitoring time of 60 days was carried out with standard DMEM. Spheroids which did not enlarge over at least three consecutive time points and did not regrow to $>200 \mu \mathrm{m}$ were declared as "controlled".

Growth delay values $\left(t_{\mathrm{SGD}}\right)$ as depicted in "Growth and regrowth experiments" could be reliably calculated only for treatment arms showing 100\% regrowth, e.g. for low doses of irradiation. For higher doses, the proportion of controlled spheroids was documented as function of time. The spheroid control probability (SCP) refers to the proportion of 
spheroids that has lost regrowth capacity upon treatment. SCP values were documented as function of the irradiation dose, and curves were fitted with a sigmoid dose-response model according to the tumor control probability in vivo assay (e.g. [19].) using the following function ( $D$-dose; $a$, $b$-variables)

$\mathrm{SCP}=1-\frac{1}{1+\mathrm{e}^{(-a-b \ln D)}}$

Subsequently, the spheroid control dose $50\left(\mathrm{SCD}_{50}-\right.$ radiation dose leading to a loss of growth recovery in $50 \%$ of the spheroids) was calculated, and the quotient of $\mathrm{SCD}_{50}$ values for treatment arms of interest was determined as dose reduction factors (DRF).

\section{Reverse transcription (RT)-PCR analysis}

Cells were seeded at defined concentration in monolayer culture and samples were collected at different time points $(0-120 \mathrm{~h})$ throughout treatment to isolate total cellular RNA using the RNeasy Mini Kit (Qiagen) according to the manufacturer's instructions. RNA concentrations and purity were assessed spectrophotometrically with a Nanodrop 1000 spectrophotometer (Thermo Fisher Scientific). cDNA was synthesized from each sample using the Verso cDNA Synthesis Kit (Thermo Fisher Scientific) and $1 \mu \mathrm{g}$ of total RNA. PCR was carried out in an MJ Research PTC-200 Thermal Cycler (Bio-Rad) using the GoTaq Flexi DNA Polymerase Kit (Promega) and specific primers for relevant ER stress response genes. Primer pairs with product sizes are listed in Table S1. Conditions for the PCRs were as follows: initial denaturation at $95{ }^{\circ} \mathrm{C}$ for $7 \mathrm{~min}$, denaturation in cycles at $95{ }^{\circ} \mathrm{C}$ for $30 \mathrm{~s}$, annealing $46-55^{\circ} \mathrm{C}$ for $30 \mathrm{~s}$, extension $72^{\circ} \mathrm{C}$ for $1 \mathrm{~min}$, and a final step at $72{ }^{\circ} \mathrm{C}$ for $5 \mathrm{~min}$. PCR products were separated by $2.0 \%$ agarose gel electrophoresis, visualized by RedSafe (iNtRON Biotechnology) dye staining, and documented using the GeneGenius Gel Imaging System (Syngene). The spliced (415 bp) and unspliced (441 bp) variants of XBP1 mRNA were resolved by $4 \%$ agarose gel electrophoresis as described previously [23]. Human-specific $A C T B$ gene primers were applied as reference.

\section{Real-time quantitative (q-)PCR analysis}

Total cellular RNA from defined treated and untreated monolayer cell samples was extracted and cDNA was synthesized as described above. The specific primer sequences for the analyzed genes were identical to the RT-PCR approaches (Table S1). cDNA was diluted (1:10) and the one step PCR reaction was performed in a total volume of $20 \mu \mathrm{L}$ using the GoTaq qPCR Master Mix (Promega) according to the manufacturer's protocol. The PCR condition was set at an initial denaturation at $95{ }^{\circ} \mathrm{C}$ for $10 \mathrm{~min}, 45$ cycles at $95{ }^{\circ} \mathrm{C}$ for $15 \mathrm{~s}$ and $57^{\circ} \mathrm{C}$ for $1 \mathrm{~min}$. Data were collected and analyzed using the Applied Biosystems StepOnePlus Real-Time PCR System with v.2.2.2 StepOne Software (Life Technologies, Applied Biosystems). The relative gene expression of control versus treated cells was assessed by the comparative threshold cycle $(\triangle \Delta \mathrm{Ct})$ method using $A C T B$ as reference control; values $\geq$ twofold were considered as differentially regulated.

\section{siRNA transfection}

Small interfering (si)RNAs for IRE1, GADD34, ATF3, ATF4 and $C H O P$ were purchased from Eurofins Genomics. Their targeting sequences are given in Table S2. Cells transfected with unspecific siRNAs (scrambled siRNA \#1, \#2 and \#3) were used as negative control. Transfection was conducted with the Lipofectamine ${ }^{\mathrm{TM}}$ RNAiMAX (Invitrogen) according to recommendations of the manufacturer. $48 \mathrm{~h}$ after transfection, cells were treated with mono- or comb-ADT for defined time intervals and then processed for PCR, western blotting or clonogenic survival assay.

\section{Western blotting (WB)}

Western blots were performed using whole cell protein extracts from 2-D and 3-D cultures as described previously [16]. Various primary antibodies (listed in Table S3) were applied according to the manufacturers' instructions to monitor specific non-phosphorylated and phosphorylated proteins of interest. Horseradish peroxidase-conjugated goat anti-mouse or anti-rabbit IgG secondary antibodies (Dako) were used for detection, and the immuno-reactive bands were visualized using a chemiluminescence detection kit (Santa Cruz Biotechnology) followed by documentation on X-ray films (GE Healthcare). Western blots were performed for $N=3$ independent experiments and band intensities were assessed in 2-3 densitometric scans per experiment (technical replicates) using the ImageJ software. Protein signals were normalized to $\alpha$-tubulin or GAPDH loading controls and related to an internal standard protein sample, e.g. scrambled siRNA-transfected cells.

\section{Metabolomics}

Large numbers of FaDu and SAS spheroids (400-500 of each) were prepared at standard size (see above) and then exposed to control or mono-ADT conditions for $24 \mathrm{~h}$. Three aliquots of six spheroids were taken per treatment arm to determine the average cell number per spheroid in the differently treated spheroid populations; FaDu and SAS spheroids were enzymatically dissociated according to an established protocol [24], and cells were counted using a Scepter Cell 
Counter Sensor (Millipore). Another 180 non-dissociated spheroids were then pooled per treatment arm, transferred into $50 \mathrm{~mL}$ Falcon tubes, washed twice with $30-50 \mathrm{~mL}$ icecold PBS including short spins $(500 \mathrm{~g})$ at $4{ }^{\circ} \mathrm{C}$ and finally resuspended in $500 \mu \mathrm{L}$ ice-cold $50 \%$ methanol for transfer into low-binding $1.5 \mathrm{~mL}$ Eppendorf tubes. Samples were frozen immediately and stored at $-80{ }^{\circ} \mathrm{C}$ until analysis. Metabolites were extracted as described earlier [25].

Samples obtained from two independent experiments with SAS and $\mathrm{FaDu}$ spheroids were then analyzed using two different metabolic profiling platforms. The first was a two-dimensional gas chromatography workflow combined with high-speed scan single quadrupole mass spectrometry (GCxGC-qMS) as detailed in [25]. The second analysis platform was a liquid chromatography-mass spectrometry (LC-MS) system consisting of an Agilent 1290 Infinity ultra-high-performance liquid chromatography system (UHPLC) equipped with a quaternary pump delivery system (G4204A), a HiP autosampler (G4226A), a column thermostat (G1316C). A BEH C18 XP Column, (130 $⿱ ㇒, 1.7 \mu \mathrm{m}$, $2.1 \mathrm{~mm} \times 150 \mathrm{~mm}$; Waters) was used for untargeted metabolomics profiling. Alternatively, an ACQUITY Glycoprotein Amide Column, (300 ̊, $1.7 \mu \mathrm{m}, 2.1 \mathrm{~mm} \times 150 \mathrm{~mm}$; Waters) was used for arginine analysis. The UHPLC system was coupled to a 6560 Ion mobility QTOF LC/MS mass spectrometer (Agilent Technologies) equipped with a Jetstream ESI-AJS source.

For arginine analysis by LC-MS, dried metabolite extracts were re-suspended $20 \mu \mathrm{L}$ per million cells in water (LC-MS graded from Merck) with $0.1 \%$ formic acid (FA, LC-MS graded from Fisher Scientific). Data were acquired by LC-MS in QToF mode using positive electrospray ionisation (ESI+). Two reference ions, $m / z, 121.0508$ and 922.0097 were used as internal standards. The Dual AJS ESI settings were as follows: gas temperature: $300{ }^{\circ} \mathrm{C}$, the drying gas: 8 $\mathrm{L} / \mathrm{min}$, nebulizer $35 \mathrm{MPa}$, sheath gas temperature $350^{\circ} \mathrm{C}$, sheath gas flow $11 \mathrm{~L} / \mathrm{min}$, Vcap $3.500 \mathrm{~V}$ and nozzle voltage $1000 \mathrm{~V}$. The fragmentor of the mass spectrometer TOF was set to $400 \mathrm{~V}$.

The UHPLC gradient was composed of $20 \%$ buffer A [water $(0.1 \% \mathrm{FA})$ ] and $80 \%$ buffer B [Acetonitrile (LC-MS graded from Merck) $(0.1 \% \mathrm{FA})]$ with a flow rate of $0.30 \mathrm{~mL}$; 0-8 $\min 20-35 \%$ A; 8-9 min 35-20\% A. The gradient was followed by a 3-min post-time to re-equilibrate the column. The external standard, L-arginine monohydrochloride (Sigma-Aldrich), was used for its identification.

For untargeted metabolomics analysis by LC-MS, samples of metabolite extracts were re-suspended in $20 \mu \mathrm{L}$ per million cells of $60 \%$ acetonitrile in water $(5 \mathrm{mM}$ ammonium formate [LC graded from Sigma-Aldrich)]. The data were acquired by LC-MS in QToF mode using positive electrospray ionisation (ESI+). Two reference ions, $m / z, 121.0508$ and 922.0097 were used as internal standards. The Dual AJS
ESI settings were as follows: gas temperature: $325^{\circ} \mathrm{C}$, the drying gas: $5 \mathrm{~L} / \mathrm{min}$, nebulizer $35 \mathrm{MPa}$, sheath gas temperature $275^{\circ} \mathrm{C}$, sheath gas flow $12 \mathrm{~L} / \mathrm{min}$, Vcap $4.000 \mathrm{~V}$ and nozzle voltage $500 \mathrm{~V}$. The fragmentor of the mass spectrometer TOF was set to $400 \mathrm{~V}$.

The gradient in a total analysis time of 42 min started by a 5-min isocratic gradient composed with $95 \%$ buffer A [ $60 \%$ acetonitrile in water (5 $\mathrm{mM}$ ammonium formate)] and 5\% buffer B [10\% acetonitrile in 2-propanol (LC-MS graded from Fisher Scientific) (5 mM ammonium formate)] with a flow rate of $0.25 \mathrm{~mL}$ and was followed by steps: 5-7 min $95-50 \%$ A; 7-25 min 50-5\% A; 25-30 min 5\% A; 30-30.1 min 5-95\% A 30.1-35 min 95\% A. The gradient was followed by a $7 \mathrm{~min}$ post time to re-equilibrate the column.

The raw LC-MS data were processed and analyzed using the MassHunter Workstation software package (Agilent Technologies, version B8.0). Further data analysis was performed through XCMS Online [26, 27]. GCxGC data analysis was performed as described previously [25].

\section{Experimental setup with non-malignant cells}

The human retinal pigment epithelial cell line ARPE-19 (ATCC), human foreskin fibroblasts established earlier in our laboratory [28] and human umbilical vein endothelial cells (HUVEC) isolated at the Division of Vascular Endothelium and Microcirculation, Department of Medicine III, Medical Faculty and University Hospital Carl Gustav Carus, TU Dresden, Germany, according to [29] served as normal cell reference. In contrast to the established cell lines, HUVEC and fibroblasts were re-cultured from low passage frozen stocks ( $\mathrm{P} 1$ and $\mathrm{P} 3$, respectively), and used for 3-D cell culture experiments at with a CPD $<10$. Standard DMEM as described for cell lines was also used for culturing normal cells with the following exception: all media for HUVEC were additionally supplemented with $0.5 \%$ self-isolated retina calf eye growth supplement as highlighted in [29]. One batch of fibroblasts (VF2) and two different pooled HUVEC preparations were applied in the present study. VF2 fibroblast and ARPE-19 cells were studied in $N \geq 3$ independent experiments with $n=2-3$ biological repeats while the HUVEC preparations were used in individual experimental series with $n=3$ biological repeats.

For experimental setup, normal cells were seeded into 96-well plates according to the spheroid liquid overlay approach; $1 \times 10^{4}$ (HUVEC, fibroblasts) or 5000 cells (ARPE-19) were inoculated per well and the resulting 3-D cultures (single aggregate per well) at day 4 were monitored and treated with mono- or comb-ADT for up to 7 days. Two to three aliquots of 8-12 spheroids from each treatment arm were collected at defined time points and enzymatically dissociated for cell counting. The average number 
of membrane-intact cells per spheroid was determined for each treatment arm and experiment, and the viability was assessed as cell number in treated relative to the respective untreated cultures that were kept under + Arg conditions for the same time period.

\section{Bioinformatics and statistical analyses}

Bioinformatic analysis of the TCGA dataset was conducted on processed RNA-seq array, gene alteration data, and paired clinical feature data downloaded through the cBioPortal (http://www.cbioportal.org). Microarray data processing, Kaplan-Meier curves of patient data, heatmaps, correlation analyses and log rank statistics were performed in Small Utilities of Microarray Data Analysis (SUMO) software.

All values within the text and figures referring to 2-D culture data are presented as mean \pm SD from three independent experiments each with $\geq 3$ biological replicates $(N=3, n \geq 3)$, as described in the figure legends. Treatment groups of interest were compared for all time points using a two-way ANOVA test. Clonogenic survival was characterized with the linear-quadratic model and $p$ values were determined by Mann-Whitney test with Bonferroni-Holm correction using IBM SPSS Statistics as described previously in $[13,15]$. ANOVA comprising Bonferroni correction was applied for 3-D cell growth assays while logistic regression was employed to compare $\mathrm{SCD}_{50}$ values as well as DRF and to fit the corresponding spheroid control probability curves. Subsequent bootstrapping with 1000 samples was performed using STATA/SE 11.2 (StataCorp LLC, TX, USA) to determine $95 \%$ confidence intervals and estimate statistical significance. A minimum of 30 individual spheroids were monitored for each treatment arm and irradiation dose. Values are documented according to their significance level as $p<0.05(*), p<0.01(* *)$, and $p<0.001(* * *)$.

\section{Results}

\section{Mono-ADT induces heterogeneous growth arrest in HNSCC cells}

To examine the efficacy of mono-ADT in HNSCC, we initially compared cell growth and re-growth capacity in 9 different $\mathrm{HPV}^{-}$HNSCC cell lines in 2-D culture under control (+Arg) and Arg-free ( - Arg) conditions over a period of up to 9 days. All cell lines responded to mono-ADT with an acute growth arrest (Fig. 1a; Table S4A), and in some cases the number of viable cells even decreased with exposure time indicating that Arg is an essential amino acid for HNSCC cell growth in vitro. Growth recovery (i.e. ability to resume growth) after different intervals of mono-ADT was assessed 3 days after termination of treatment and re-transfer to standard Arg-rich conditions. HNSCC cells showed a highly variable extend of growth restoration. The ability to recover after Arg starvation decreased time-dependently for SAS, HSC4, XF354, UT-SCC-8 and UT-SCC-14 cells, but remained largely unaltered after incremental periods of treatment for Cal-33, FaDu, UT-SCC-5, and UT-SCC-15 cells. This suggests that the latter cell lines are intrinsically more resistant (non-responders) to mono-ADT in spite of the general growth arrest during treatment (Fig. 1a; Table S4A).

It is well established that ASS is the rate-limiting enzyme for the biosynthesis of Arg from Cit and one determinant of Arg auxotrophic response in vivo [7, 8]. We, therefore, analyzed the levels of this marker enzyme in the HNSCC cell lines and, also monitored growth and growth recovery, respectively, upon exposure to Arg-deprived, Cit-conditioned $(0.04 \mathrm{mM})$ medium, which better mimics the in vivo conditions of ADT. All HNSCC cells were ASS-positive. However, the heterogeneous ASS protein levels strongly correlating with ASS1 gene expression (Fig. S1A-C) in the cell lines did not reflect their divergent capacity for sustained growth under mono-ADT in the presence of Cit (Fig. S1D). Although Cit in principle supported growth recovery after completion of the treatment, it could not rescue all sensitive cell lines from acute ADT-induced growth arrest.

\section{Mono-ADT efficiently sensitizes selected HNSCC cells to irradiation}

Radio(chemo)therapy is the contemporary standard-of-care in the curative-intent management of HNSCC patients [30]. $\mathrm{We}$, therefore, addressed the impact of mono-ADT $(24 \mathrm{~h}$ pre-treatment) on the radioresponse of HNSCC cells via 2-D clonogenic survival assays. Significant radiosensitization upon mono-ADT was seen in six out of nine tested cell lines. No general overlap between mono-ADT dependent growth restoration capacity and radiosensitization was observed. Radiosensitization was particularly prominent in the intrinsic ADT-responder cell lines SAS, HSC4, and XF354 where physiological Cit concentrations turned out to be insufficient for compensating the effect (Fig. 1b; Table S4B), whereas $\mathrm{FaDu}$, UT-SCC-5 and UT-SCC-15 proved to be general non-responders.

In contrast to the regrowth capacity, we observed a positive correlation of intermediate strength (not yet significant) between ASS protein content in the HNSCC models in vitro and their radiosensitivity as reflected by the dose required to reduce clonogenic survival to $0.1 \%$ ( $0.1 \%$ surviving fraction dose-SFD) (Fig. S2A). Regardless of pathophysiological phenomena that are not reflected in the in vitro assay, but can drive radioresistance in vivo such as hypoxia, the $0.1 \%$ SFD values well correlate with the in vivo "curative" endpoint $\mathrm{TCD}_{50}$ (irradiation dose required to control the disease in $50 \%$ of tumor-bearing mice) published earlier for xenografts 


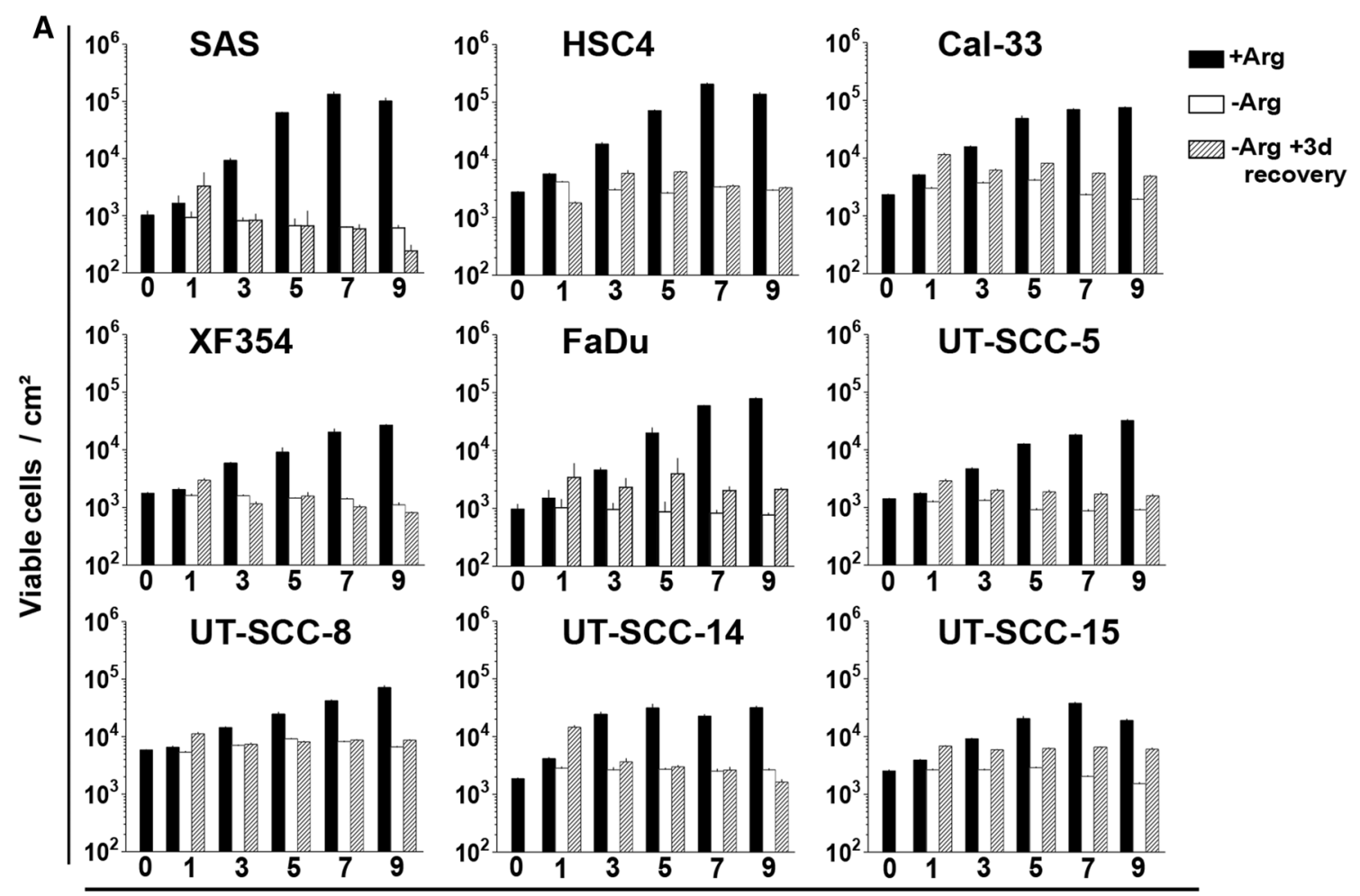

Time of exposure [d]
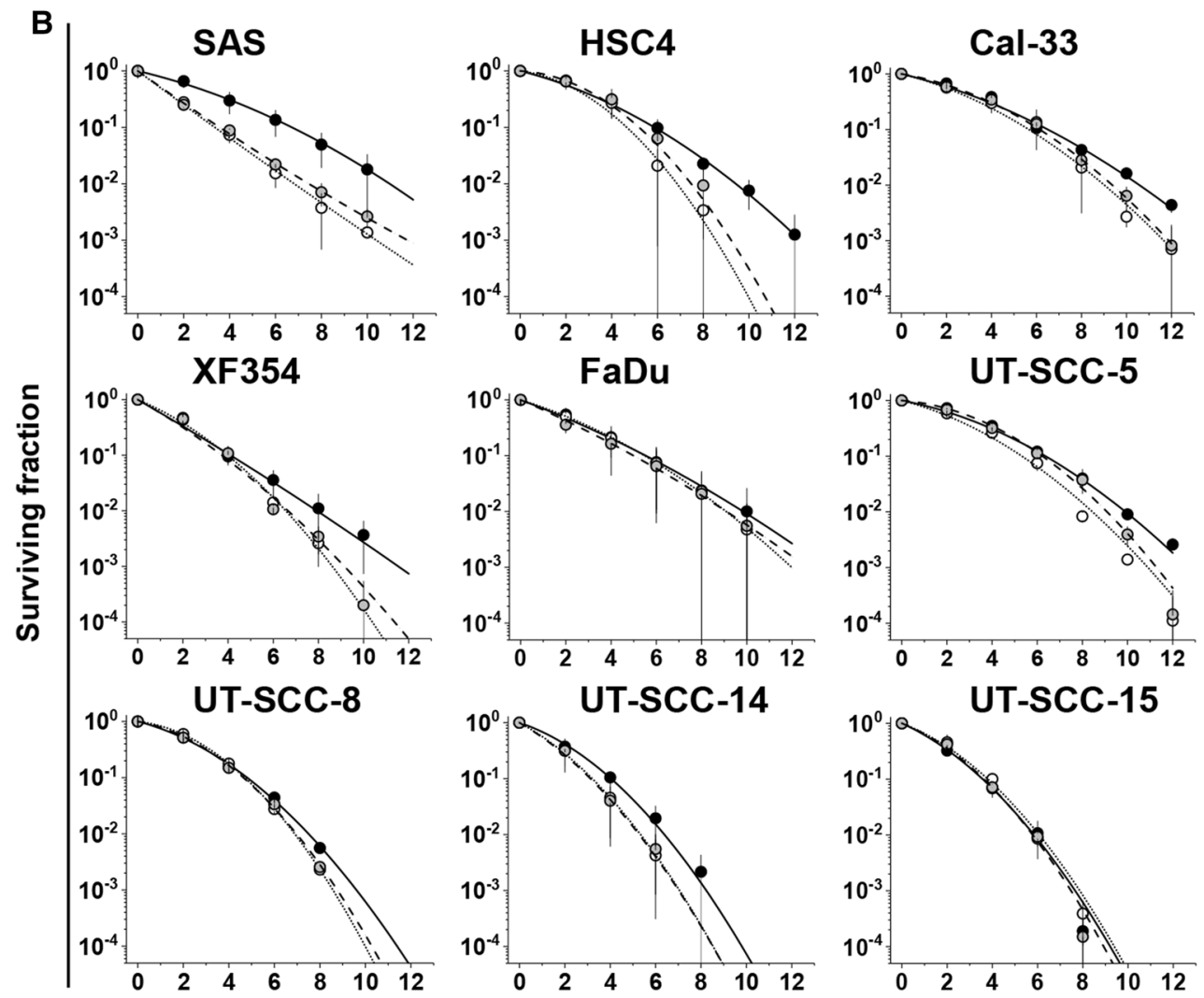

+ Arg
-Arg
0 -Arg +Cit

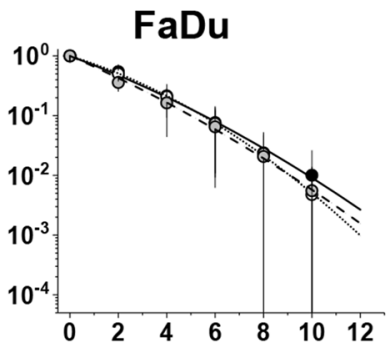

UT-SCC-5
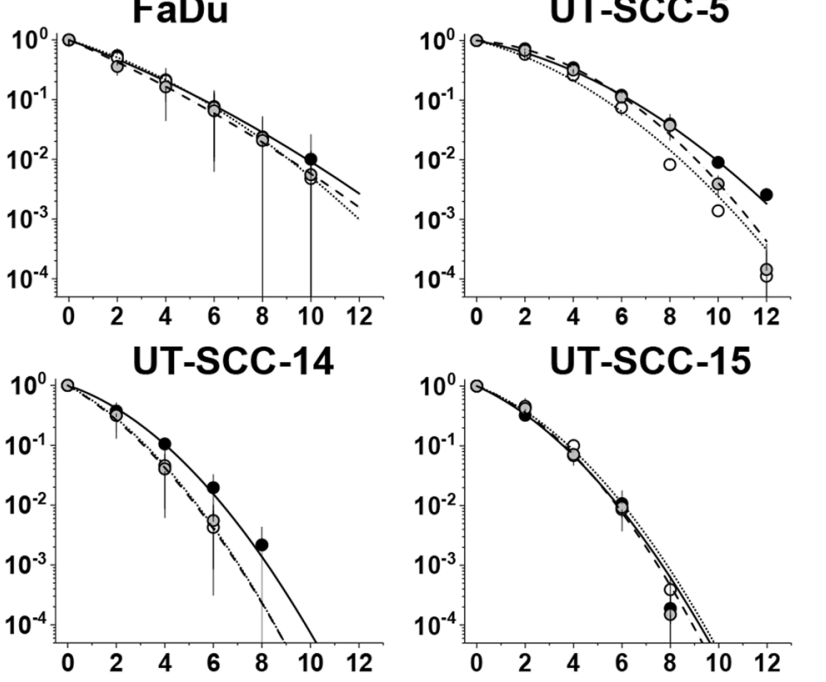

Irradiation dose [Gy] 
४Fig. 1 Mono-ADT induces heterogeneous growth arrest and efficiently sensitizes selected HNSCC cells to irradiation. All data show means $( \pm \mathrm{SD})$ from three independent experiments of nine HNSCC cell lines in 2-D culture each with $\geq 3$ biological replicates $(\mathrm{N}=3$, $n \geq 3$ ). a Growth and regrowth of cells exposed to Arg-rich (+ Arg) or Arg-free conditions (- Arg) for 1-9 days. Medium was exchanged after treatment to standard ( + Arg) for an additional period of 3 days to allow growth recovery. $\mathbf{b}$ Clonogenic survival of cells pre-exposed for $24 \mathrm{~h}$ to + Arg or - Arg conditions with or without $0.04 \mathrm{mM}$ Cit. Cells were irradiated with single doses of 0-12 Gy and then allowed to form single cell colonies. Data were fitted with a linear-quadratic model

derived from the same HNSCC cell line panel (Fig. S2B) [20]. Based on these data, we propose a link between ASS expression and intrinsic radioresistance in HNSCC cells which is apparently unrelated to the mono-ADT-induced radiosensitization mechanisms.

\section{Mono-ADT triggers massive and durable ER stress}

Nutrient deficiency and cellular metabolic stress are sensed by the ER. Hence, mono-ADT most likely induces ER stress responses in HNSCC cells. We examined the activation of ER stress signaling cascades upon mono-ADT in two representative HNSCC cell lines, i.e. SAS as a responder and $\mathrm{FaDu}$ as a non-responder model. Levels of several marker genes and proteins involved in the ER stress response pathways were examined by RT-PCR and Western blot (WB) analyses. Notably, both HNSCC cell lines are defective in functional p53 (https://p53.iarc.fr/CellLines.aspx), and differential ADT-induced effects as documented in the following chapters can thus not be attributed to this tumor suppressor as indicated in earlier studies $[15,16]$.

Mono-ADT (in contrast to comb-ADT as documented later in Figs. 2e and 3c) did not significantly enhance the expression of the classical ER stress marker gene GRP78 in the HNSCC cell line models. However, we detected a reproducible time-dependent upregulation of the ER sensor genes IREI and ATF6, which was clearly more pronounced in SAS than FaDu cells (Fig. 2a). The IRE1 mRNA level reached a maximum after 8-16 $\mathrm{h}$ of Arg deprivation and then gradually declined. Activated IRE $1 \alpha$ cleaves its premRNA substrate X-box binding protein 1 (XBP1) mRNA to initiate an unconventional splicing reaction and produce mature $s X B P 1$ (spliced XBPI) mRNA [23]. A strong splicing reaction of $X B P 1 \mathrm{mRNA}$ after $8 \mathrm{~h}$ of Arg starvation was detected exclusively in SAS cells (Fig. 2a; lower band). In FaDu cells, $s X B P 1$ accumulation occurred only after treatment with strong ER stress inducers such as tunicamycin or when ADT was combined with canavanine (Cav) as highlighted later. The data clearly demonstrate that the responder SAS but not the non-responder FaDu cells signal via the IRE1 $\alpha$-XBP1 pathway upon mono-ADT.
Activation of PERK or GCN2 kinases during ER stress suppresses global protein translation and activates ATF4dependent translation through phosphorylation of eIF2 $\alpha$ [31]. Mono-ADT resulted in the phosphorylation of eIF $2 \alpha$ at Ser51 in both cell lines of interest with the same kinetics (Fig. 2b). Also, a constitutive time-dependent upregulation of the ATF4 gene and enhanced protein levels were observed (Fig. 2a/b). Prolonged mono-ADT further resulted in decreased phosphorylation and thus deactivation of the main mTOR target, ribosomal p70 S6 kinase, which participates in the cellular translation machinery (Fig. 2b).

The duration of eIF $2 \alpha$ phosphorylation and translational inhibition depends on the activation of the protein phosphatase PP1, which dephosphorylates eIF $2 \alpha$, thereby restoring global mRNA translation [32, 33]. In this regard, a strong time-dependent induction of the corresponding GADD34 (PPP1R15A) gene expression was recorded only in SAS cells, whereas GADD34 mRNA levels in FaDu cells initially increased and then gradually declined to basal levels at $24 \mathrm{~h}$ of Arg starvation (Fig. 2a). Figure 2a also documents that mono-ADT up-regulated the autophagy genes downstream of ATF4, e.g. ATG12 and SQSTM1 (p62), in SAS but not in $\mathrm{FaDu}$ cells; their products are the main components of autophagosome formation. Nonetheless, FaDu cells showed a severe treatment time-dependent formation of lipidated LC3-II protein, a well-known marker of autophagy, while SAS cells elicited high basal level of autophagy even without treatment (Fig. 2b).

Taken together, our data strongly suggest that mono-ADT triggers a massive and long-term ER stress induction, mainly via the IRE1 $\alpha$-sXBP1 and eIF2 $\alpha$-ATF4 signaling pathways, which is either exclusive or substantially more pronounced in the responder (SAS) than the non-responder $(\mathrm{FaDu})$ cells.

\section{Mono-ADT-induced apoptosis is partially linked to ER stress}

ER stress is inherently linked to apoptosis [17, 34]. Therefore, we monitored the activation of the main pro-survival and pro-apoptotic pathways in SAS and FaDu cells upon mono-ADT. First, we analyzed the level of phosphorylated (Ser473) Akt protein in Arg-starved cells and found a rapid increase in phosphorylated protein solely in SAS cells; the phosphorylation level of Akt protein in FaDu cells was unaffected (Fig. 2b). Similarly, the amount of phosphorylated Erk1/2 protein in SAS cells started to decrease $72 \mathrm{~h}$ after the onset of Arg starvation but did not systematically change in the FaDu model (Fig. 2b). These observations reveal that both Akt- and MAPK-mediated signaling pathways are involved in sustaining SAS cell survival upon mono-ADT.

One of the major factors contributing to ER stress-mediated cell death is CHOP $[35,36]$. Expression of $C H O P$ was gradually up-regulated upon mono-ADT in SAS cells. In 
A
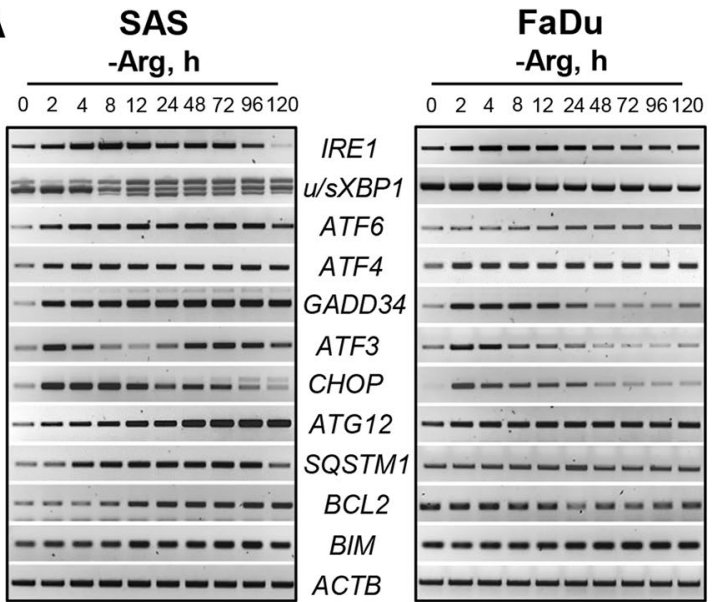

C

SAS

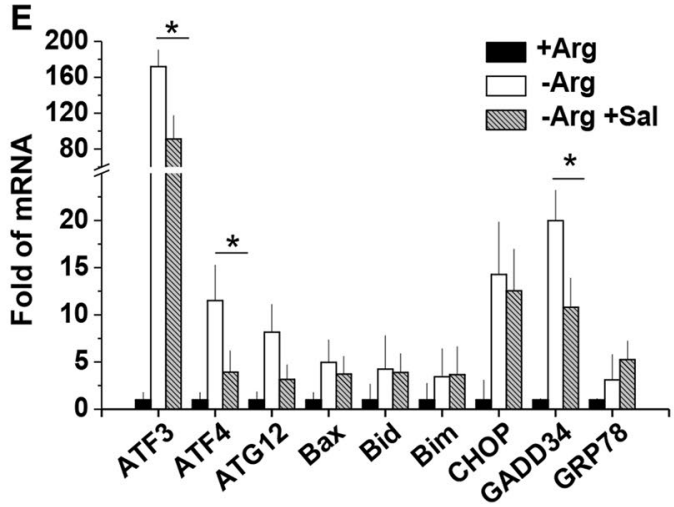

Fig. 2 Mono-ADT triggers massive and durable ER stress which is partially linked to apoptosis. All data show representative or averaged results of three independent experiments $(N=3)$ for SAS $(\mathbf{a}-\mathbf{e})$ and $\mathrm{FaDu}(\mathbf{a} / \mathbf{b}) 2$ 2-D cultures; the ER stress modulator salubrinal (Sal) was added at $0.02 \mathrm{mM} 1 \mathrm{~h}$ before ADT. a Representative RT-PCR data sets documenting the expression of several ER stress response genes in cells exposed to - Arg medium for up to $120 \mathrm{~h}$ or left untreated $(0 \mathrm{~h}) . A C T B$ gene was used as reference. b Representative western blots for various proteins of interest in cells treated according to $\mathbf{a}$. $\alpha$-tubulin ( $\alpha$-tub) was used as loading control. $\mathbf{c}$ Representative western blots of cPARP protein in SAS cells after different periods of

contrast, the kinetics of $\mathrm{CHOP}$ gene expression in $\mathrm{FaDu}$ cells was similar to that of GADD34 showing a decline within the first $24 \mathrm{~h}$ of Arg starvation (Fig. 2a). Unexpectedly, we noticed two peaks of induction for ATF3 mRNA in SAS cells throughout the $120 \mathrm{~h}$ treatment period, whereas FaDu cells
B SAS
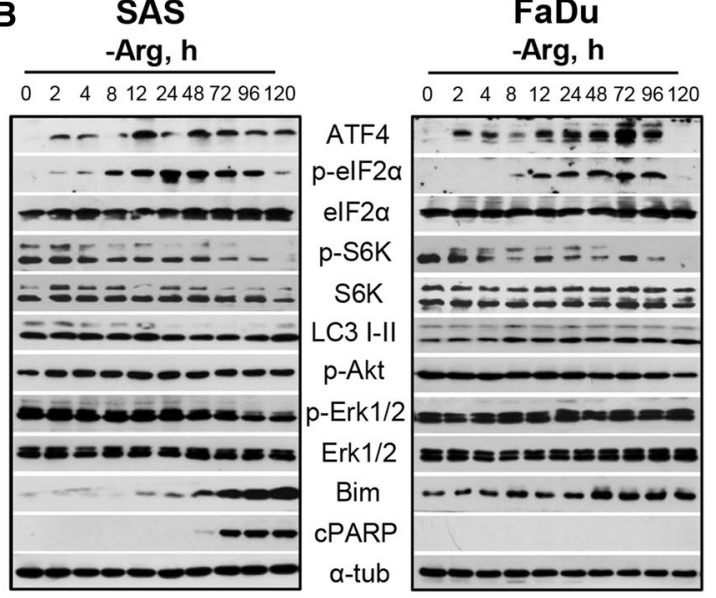

D

\section{SAS}
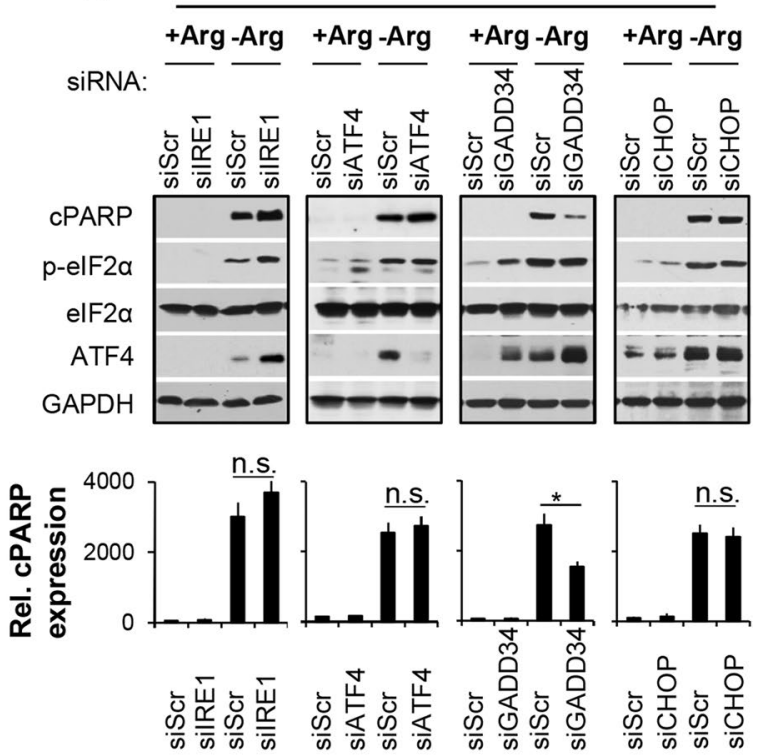

mono-ADT (1-5 days) with or without Sal. d Representative western blots for proteins of interest in siRNA-mediated knockdown SAS cells treated with mono-ADT. Cells were transfected with siRNAs (IRE1, ATF4, GADD34 and CHOP) and then exposed to+Arg or - Arg conditions for $72 \mathrm{~h}$. Non-specific siRNAs were used as control (siScr). Mean values $( \pm \mathrm{SD})$ from densitometric analysis of the relative cPARP expression normalized to GAPDH are documented in the lower panel; ${ }^{*} p \leq 0.05 ;$ n.s. not statistically significant. e Level of ER stress response genes measured by qPCR in SAS cells upon $72 \mathrm{~h}$ of Arg deprivation with or without Sal. Data normalized to ACTB gene are shown as means $( \pm \mathrm{SD}) ; * p \leq 0.05$

only showed the characteristic up-regulation at $2-4 \mathrm{~h}$ of $\mathrm{Arg}$ starvation followed by normalization of ATF3 gene expression (Fig. 2a). This implies that the delayed but not early ATF3 response plays a role in stress-induced apoptosis during amino acid starvation $[37,38]$. Accordingly, continuing 

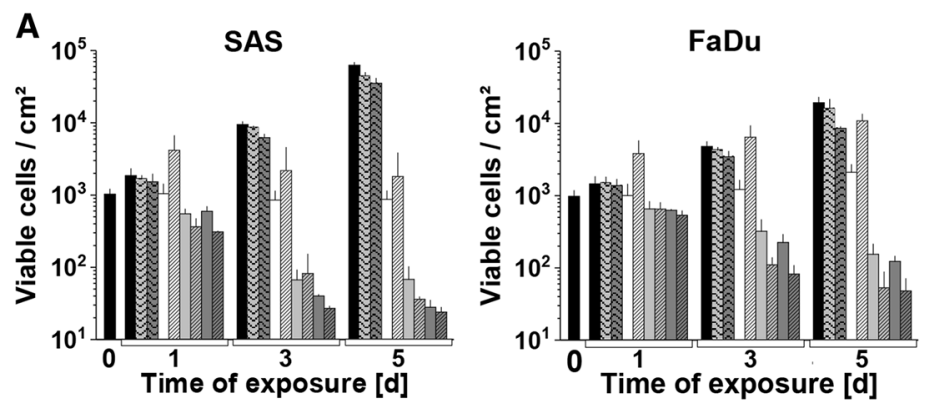

+ Arg

$+\mathrm{Arg}+0.05 \mathrm{mM}$ Cav

Q + Arg $+0.1 \mathrm{mM} \mathrm{Cav}$

$\square$-Arg

$\square \cdot-\operatorname{Arg}$ - 3 d recovery

$-\mathrm{Arg}+0.05 \mathrm{mM}$ Cav

$-A r g+0.05 \mathrm{mM}$ Cav $+3 \mathrm{~d}$ recovery

$-A r g+0.1 \mathrm{mMCav}$

- Arg $+0.1 \mathrm{mM}$ Cav $+3 \mathrm{~d}$ recovery

B
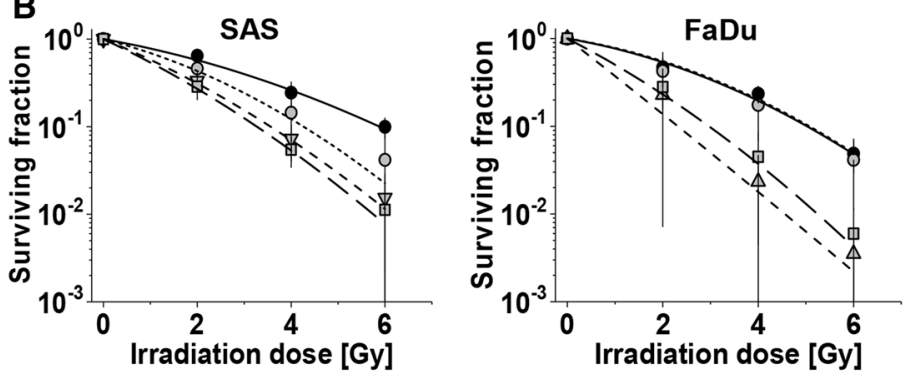

- + Arg

-Arg +Cit

$\nabla-$ Arg +Cit $+0.01 \mathrm{mM} \mathrm{Cav}$

$\square-A r g+C i t+0.05 \mathrm{mM}$ Cav

$\Delta$-Arg + Cit + $0.1 \mathrm{mM}$ Cav
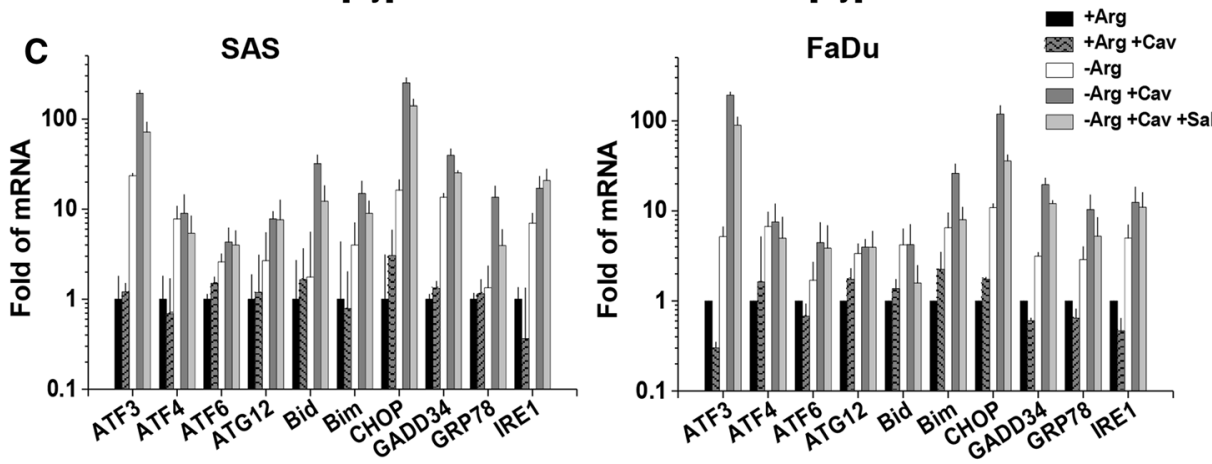

D
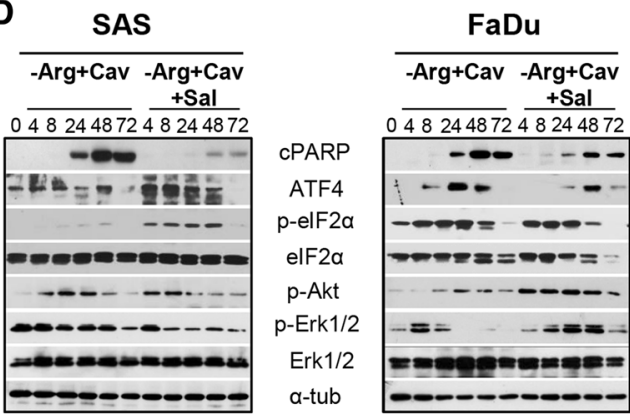

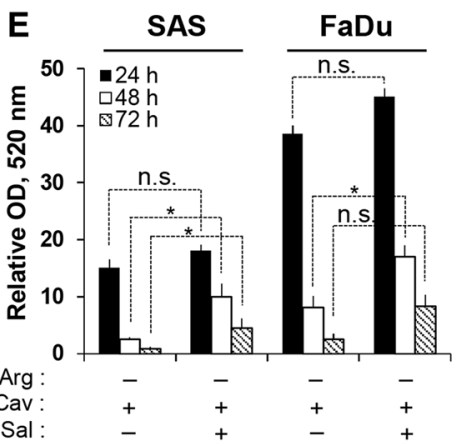

Fig. 3 Arg analog-Cav strongly augments the efficacy of mono-ADT and results in catastrophic ER stress and apoptosis. All data show means $( \pm$ SD) from three independent experiments with $\geq 3$ biological replicates each $(N=3, n \geq 3)$ in SAS and FaDu 2-D cultures; salubrinal (Sal) was applied according to Fig. 2. a Cell count per surface area after different periods of mono- and comb-ADT with $0.05-0.1 \mathrm{mM}$ $\mathrm{Cav}(0-5$ days) in the presence of $0.04 \mathrm{mM}$ Cit and 3 days after termination of treatment (3-day recovery). $\mathbf{b}$ Clonogenic survival of cells irradiated with single doses of 0-6 Gy under either standard conditions or upon $24 \mathrm{~h}$ pre-exposure to - Arg medium with and with- out $0.04 \mathrm{mM}$ Cit and 0.01-0.1 mM Cav. Data were fitted according to Fig. 1b. c Level of ER stress response genes of interest (qPCR) upon $24 \mathrm{~h}$ of $\mathrm{Arg}$ deprivation with and without $0.1 \mathrm{mM} \mathrm{Cav}$ and/ or Sal. Data were normalized to ACTB mRNA level. d Representative western blots showing proteins of interest in cells incubated in - Arg medium with $0.1 \mathrm{mM}$ Cav for up to $72 \mathrm{~h}$ with and without Sal; $\alpha$-tubulin ( $\alpha$-tub) was used as loading control. e MTT assay readout reflecting the relative number of viable cells after 24-72 h comb-ADT with and without Sal. Data are presented as mean $\mathrm{OD}_{520 \mathrm{~nm}} \pm \mathrm{SD}$; ${ }^{*} p \leq 0.05 ; n . s$. not statistically significant 
Arg-withdrawal in the SAS cell model transcriptionally upregulated the Bcl-2 family members $B I M$ and $B C L 2$ (Fig. 2a) and resulted in an accumulation of the caspase substrate poly(ADP-ribose) polymerase protein 1 cleaved form (cPARP) as well as Bim proteins $72 \mathrm{~h}$ after the onset of mono-ADT (Fig. 2b).

We next applied a chemical inhibitor of ER stressinduced apoptosis and selective siRNA-mediated knockdown approaches to further elucidate the link between ER stress and programmed cell death in Arg-deprived SAS cells. First, cells were exposed to the specific inhibitor of eIF $2 \alpha$ dephosphorylation salubrinal (Sal, $0.02 \mathrm{mM}) 1 \mathrm{~h}$ before and during mono-ADT to selectively block the main ER stressinduced apoptotic pathway [39]. WB analysis revealed that mono-ADT-dependent apoptosis in SAS cells reflected by cPARP protein is weaker (and/or delayed) and thus partially reduced in the presence of the ER stress modulator Sal (Fig. 2c). q-PCR analyses of several relevant genes to determine whether Sal pre-treatment diminishes global ER stress response in SAS cells are documented in Fig. 2e. $72 \mathrm{~h}$ of mono-ADT strongly enhanced ATF3, ATF4, ATG12, $G A D D 34$ and $C H O P$ gene expression (more than tenfold) in SAS cells; Sal pre-administration significantly inhibited the ADT-dependent upregulation of ATF4, ATG12, ATF3 and $G A D D 34$ gene expression. However, in parallel no reduction in the expression of GRP78, CHOP, BAX, BID and BIM genes was observed (Fig. 2e). This suggests that transcriptional upregulation of the Bcl-2 family members in SAS cells upon mono-ADT might be independent from ER stress response.

IRE1, ATF4, GADD34, and CHOP siRNA-mediated gene knockdowns were performed to identify potential ER stress-related mechanism involved in ADT-dependent apoptosis in the SAS model. As verified by q-PCR, transient transfection of siRNAs strongly down-regulated the expression of the respective target transcripts in the cells of interest (documented later in Fig. 5b). Knockdown of IRE1 slightly enhanced the expression of cPARP protein upon mono-ADT (Fig. 2d). Interestingly, ATF4 protein expression and the phosphorylation level of eIF $2 \alpha$ were also higher in IRE1-knockdown SAS cells. These data support the hypothesis that the IRE1 $\alpha$-XBP1 signaling arm is primarily a pro-survival pathway upon mono-ADT. Moreover, knockdown of the genes ATF4 and CHOP, respectively, did not significantly alter mono-ADT-induced apoptosis in SAS cells (Fig. 2d). However, siRNA-mediated knockdown of GADD34 significantly reduced the mono-ADT-dependent expression of cPARP and apoptosis induction which is in line with the Sal pre-treatment data.

Taken together, mono-ADT-related cell death in the responder SAS cells is not exclusively initiated via ER stress response and pro-apoptotic CHOP induction.

\section{Arg analog Cav strongly augments the efficacy of ADT = Comb-ADT}

We previously reported that the Arg analog Cav is selectively cytotoxic at low doses for several cancer cell types under mono-ADT but not in an Arg-rich environment [9]. Importantly, Cav $\mathrm{IC}_{50}$ values of these cells were two orders of magnitude lower in Arg-deficient than Arg-rich media. Based on these $\mathrm{IC}_{50}$ data, we assayed the effect of $0.05-0.1 \mathrm{mM}$ Cav on growth and regrowth capacity in SAS and $\mathrm{FaDu}$ monolayer cells. Both Cav concentrations showed very weak activity towards SAS and FaDu cells under Argrich conditions (Fig. 3a; Table S5A). By contrast, combADT led to a significant reduction in the number of viable cells already after $24 \mathrm{~h}$ of treatment and resulted in a loss of regrowth capacity in both cell models. Accordingly, clonogenic potential in SAS and FaDu cells was unaffected by Cav under Arg-rich conditions but critically reduced after exposure to comb-ADT (Fig. S3B; Table S5B). Although SAS cells turned out to be more sensitive to comb-ADT than FaDu cells in all growth-related assays (Fig. 3a; S3B), Cav in principle strongly enhanced the ADT-induced growthinhibitory and cytotoxic effects in both HNSCC models.

Clonogenic survival assays were applied to evaluate the impact of comb-ADT on the radioresponse. Colony formation capacity of SAS cells upon comb-ADT with $0.1 \mathrm{mM}$ Cav dropped below detection level already without irradiation. Accordingly, the more sensitive SAS cells were treated with lower concentrations of Cav $(0.01 \mathrm{mM}$ and $0.05 \mathrm{mM})$, whereas FaDu cells were exposed to $0.05 \mathrm{mM}$ and $0.1 \mathrm{mM}$ Cav for $24 \mathrm{~h}$ prior to single dose X-ray (0-6 Gy). Cav alone in an Arg-rich environment did not affect clonogenic survival upon irradiation (Fig. S3A), but comb-ADT indeed strongly intensified the radioresponse and synergistically reduced clonogenic survival not only in the more radioresistant, responder model (SAS) but also in the intrinsic nonresponder cell line FaDu (Fig. 3b).

\section{Comb-ADT results in catastrophic ER stress and apoptosis}

q-PCR analyses of numerous genes of interest were performed to determine whether comb-ADT more efficiently triggers ER stress in HNSCC cells than mono-ADT. In an Arg-rich environment, $0.1 \mathrm{mM}$ Cav did not alter the expression of various ER stress-related genes, neither in exponentially growing SAS nor in FaDu cells (Fig. 3c). As already demonstrated (Fig. 2a), 24 h of mono-ADT effectively upregulates ATF3, ATF4, IRE1, GADD34 and CHOP gene expression in SAS and FaDu cells (Fig. 3c). Almost all of the ER response genes studied herein were more dramatically 
(factor $>10$ ) enhanced by comb-ADT, e.g. IRE1, ATF3, $C H O P, G A D D 34$. In addition, comb-ADT triggered a strong splicing of $X B P 1$ mRNA not only in SAS but also in $\mathrm{FaDu}$ cells (Fig. S3C).

We next assessed comb-ADT-induced apoptosis in the two HNSCC cell line models and subsequently monitored the phosphorylation status of Erk1/2 MAPK and Akt protein kinases. A progressive accumulation of cPARP protein and apoptosis induction, respectively, was clearly observed in SAS (more pronounced) and FaDu cells after $24 \mathrm{~h}$ of combADT (Fig. 3d). The levels of p-Akt also increased during comb-ADT in both cell types, while the phosphorylation of Erk $1 / 2$ protein was differentially altered by the treatment (Fig. 3d).
Gene expression analyses revealed that most of the ER stress response genes enhanced during comb-ADT (e.g. ATF3, GADD34, CHOP, IRE1, GRP78) were less affected in SAS and FaDu cells conditioned with Sal $(0.02 \mathrm{mM})$ (Fig. 3c). Moreover, Sal pre-exposure reduced the combADT-dependent transcriptional upregulation of the proapoptotic genes BID and BIM, and it also considerably attenuated the comb-ADT-induced expression of cPARP protein in both HNSCC cell models (Fig. 3d). Conventional MTT cell viability assays further confirmed that Sal partially protected the cells from comb-ADT-related cytotoxicity (Fig. 3e); this protective effect was higher in the sensitive SAS cells. Nonetheless, comb-ADT was in principle found to cause catastrophic ER stress linked to apoptosis induction in both HNSCC cell lines.
A RT-PCR

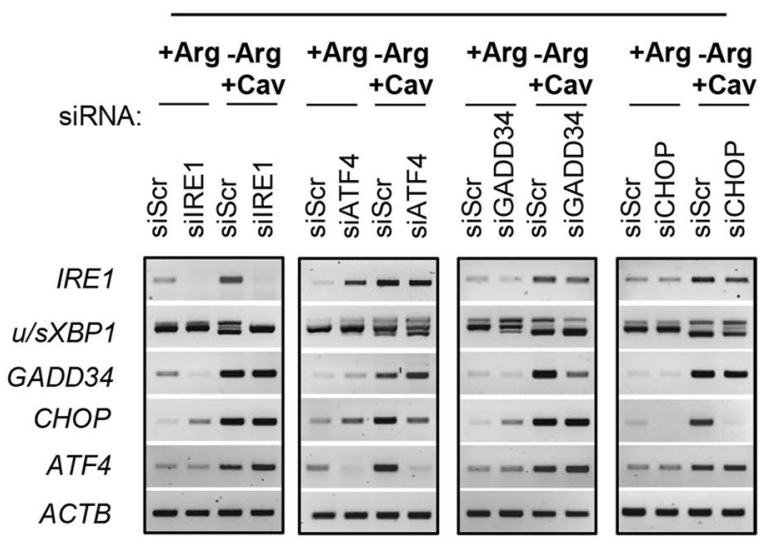

FaDu

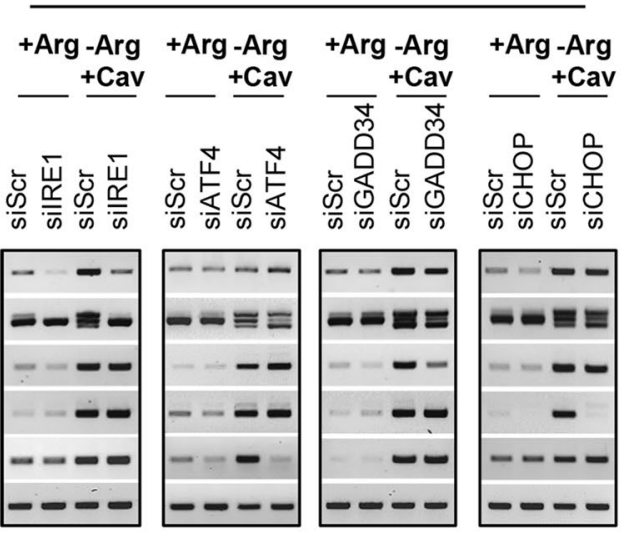

\section{B WB}
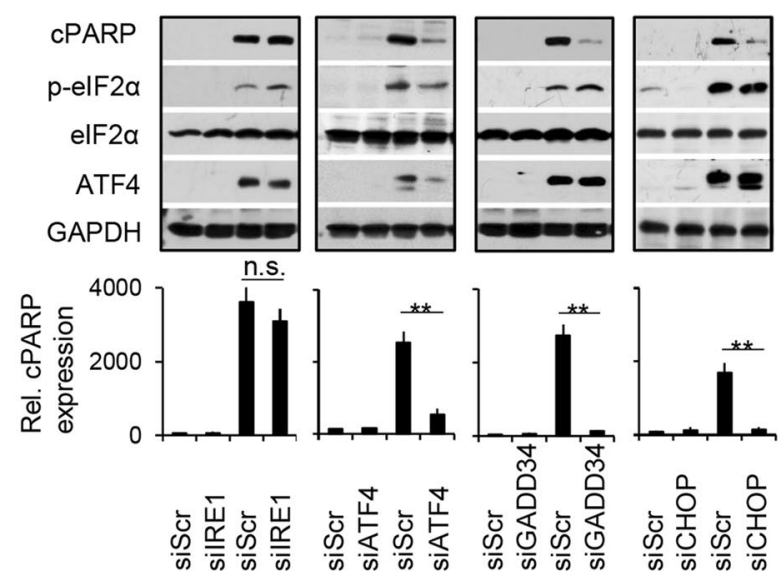
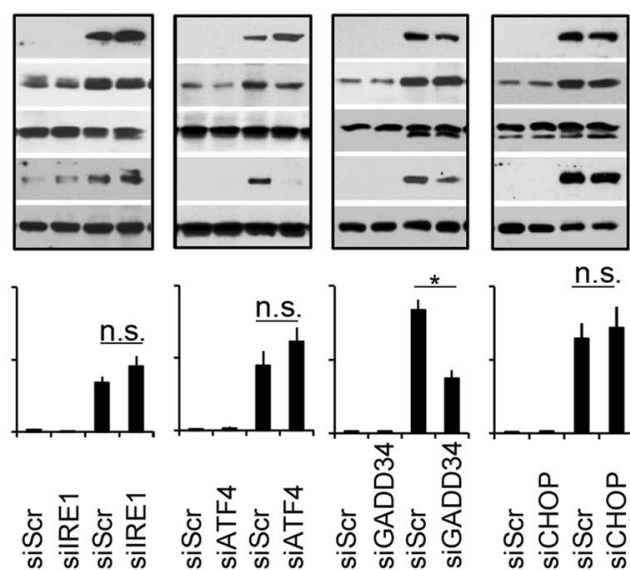

n.s.

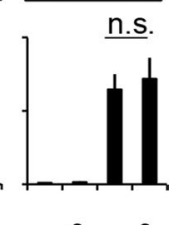

$\frac{\infty}{\omega} \stackrel{\frac{\infty}{\omega}}{\frac{\mathscr{N}}{\omega}}$

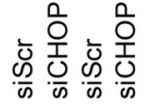

Fig. 4 eIF2 $\alpha$-ATF4(GADD34)-CHOP pathway is involved in apoptosis upon comb-ADT. Representative results of $N=3$ independent experiments in SAS and FaDu 2-D cultures are documented; cells were transfected with the respective siRNAs according to Materials and Methods, comb-ADT was achieved by exposure to - Arg medium supplemented with $0.1 \mathrm{mM}$ Cav. a RT-PCR data sets showing the expression of several ER stress response genes in siRNA- mediated knockdown cells exposed for $24 \mathrm{~h}$ to comb-ADT or control conditions. b Western blots illustrating proteins of interest in siRNAmediated knockdown cells exposed to comb-ADT or control conditions for $24 \mathrm{~h}$ (top) and densitometric analysis of the relative cPARP expression normalized to GAPDH (bottom); ${ }^{*} p \leq 0.05$; ${ }^{*} p \leq 0.01$; n.s. not statistically significant 


\section{elF2a-ATF4(GADD34)-CHOP pathway is involved in apoptosis upon Comb-ADT}

To unravel the comb-ADT-induced ER stress-apoptosis axis, we studied the role of several upregulated genes upon treatment in more detail via diverse knockdown experiments. The downregulation of the different ER stress genes of interests in all siRNA-mediated knockdown cells compared to the respective scrambled siRNA control cells are documented in Fig. 4a. Notably, knockdown of ATF4 induced an upregulation of IREI and $\triangle X B P 1$ as well as GADD34 genes in both cell types, suggesting that the cells can intrinsically compensate stress responses via an alternative IRE $1 \alpha$-sXBP1 pathway. We also found cPARP protein upon comb-ADT to be unaffected or only slightly enhanced upon knockdown of IRE1 in both cell lines (Fig. 4b). Notably, the levels of
ATF4 and p-eIF2 $\alpha$ proteins, as well as GADD34 and $C H O P$ genes were also unaltered in the siIRE1 knockdown cells (Fig. $4 \mathrm{a} / \mathrm{b}$ ). It is, therefore, likely that activation of the IRE1 $\alpha$-XBP1 pathway during comb-ADT constitutes a prosurvival response.

Interestingly, siRNA-mediated downregulation of the genes ATF4 and CHOP systematically lowered comb-ADTinduced apoptosis as reflected by reduced cPARP levels only in SAS cells but not in FaDu cells (Fig. 4b). However, in line with the Sal protection data described in the previous chapter, knockdown of GADD34 basically reduced combADT-dependent apoptosis in both cell models, notwithstanding that the effect was more pronounced in SAS cells. The integrated data thus clearly indicate that the eIF $2 \alpha$ ATF4(GADD34)-CHOP pathway plays a role in HNSCC cell death caused by comb-ADT.
A

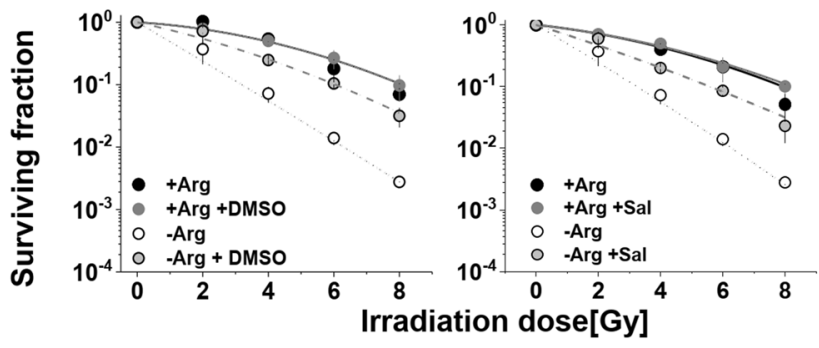

C
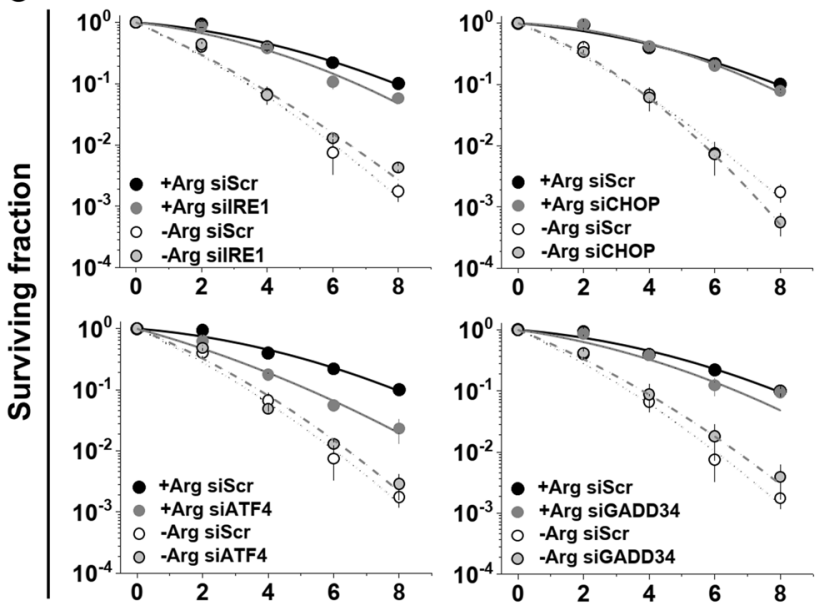

B
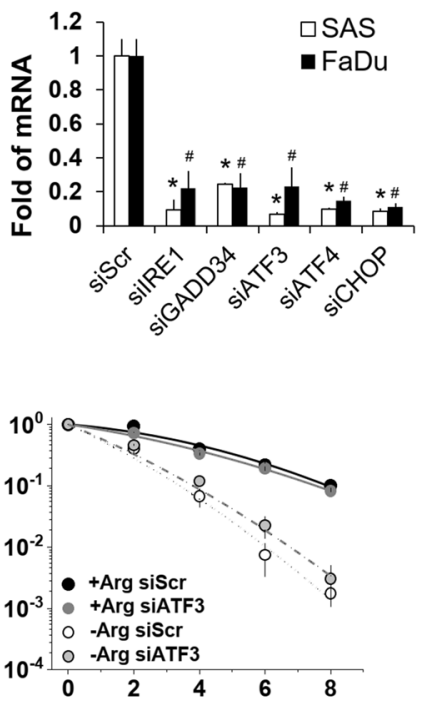

Irradiation dose [Gy]

Fig. 5 Role of ER stress in mono-ADT-induced radiosensitization mechanistically differs from comb-ADT. All graphs in $\mathbf{a} / \mathbf{b}$ show mean surviving fractions $( \pm$ SD) from three independent experiments in 2-D culture each with $\geq 3$ biological replicates $(N=3, n \geq 3)$; data were fitted according to Fig. 1. a Clonogenic survival of SAS cells irradiated with single doses of $0-8$ Gy under either standard conditions or upon $24 \mathrm{~h}$ pre-exposure to Arg-free medium with and without Sal $(0.02 \mathrm{mM})$ or dimethyl sulfoxide (2\% DMSO). b Documentation of qPCR analysis reveals sufficient knockdown of genes of interest in SAS and FaDu cells 3 days after transfection with the respective siRNAs or scrambled control (siScr). ${ }^{*} p \leq 0.01$ significant in SAS cells; ${ }^{\#} p \leq 0.01$ significant in FaDu cells. c Clonogenic survival of siRNAmediated knockdown and siScr control SAS cells irradiated with single doses of 0-8 Gy under either standard conditions or upon $24 \mathrm{~h}$ pre-exposure to Arg-free (- Arg) medium. 


\section{Mono-ADT-induced radiosensitization is linked to ER stress response but mechanistically differs from Comb-ADT}

Clonogenic survival after single dose irradiation ( $0-8 \mathrm{~Gy})$ was monitored under - Arg conditions (i) when (pre)exposed to either Sal $(0.02 \mathrm{mM})$ or to dimethyl sulfoxide (DMSO, 2\%) as ER stress modulators, or (ii) upon defined siRNA-mediated gene knockdown. The aim of this experimental setup was to demonstrate a causal relation between ER stress response and the selective radiosensitization triggered in the SAS cell model by mono-ADT.

DMSO is an efficient disaggregating agent known to prevent protein aggregation, thereby reducing ER stress signalling $[11,40]$. Notably, DMSO at the designated concentration possessed general radioprotective activity even in a + Arg environment (Fig. 5a, Table S6A). More importantly, however, both DMSO and Sal significantly diminished the radiosensitizing effect of mono-ADT (Fig. 5a), indicating a causal link between radiosensitization and ER stress response. We next recorded the radioresponse of SAS cells upon knockdown of the genes IRE1, ATF4, GADD34, ATF3 and $C H O P$. The efficiency of gene knockdown in the respective experiments is documented in Fig. 5b. Except for the knockdown of ATF4, transient transfection of siRNAs did not significantly alter the surviving fractions of SAS cells after irradiation in Arg-rich medium (Fig. 5c; Table S6B). ATF4 knockdown alone or in combination with GADD34 knockdown resulted in a slight, yet significant, sensitization of SAS cells to radiation under + Arg conditions. This finding implies that the ATF4 pathway is an inherent component in the radioresponse of SAS cells. At the same time, however, knockdown of none of these ER stress genes of interest systematically or significantly altered the radiosensitizing effect of mono-ADT (Fig. 5c; Table S6B).

To conclude, the causal link between mono-ADT-induced radiosensitization and ER stress remains an open case but clearly differs mechanistically from the ER stress-related cell response to comb-ADT.

\section{Mono- and comb-ADT-induced growth arrest and radiosensitization are revealed in 3-D models}

It was described earlier that a three-dimensional environment renders colorectal cancer cells less susceptible to single amino acid starvation [41]. We, therefore, intended to prove the efficacy of ADT in HNSCC cells in a 3-D cellular context using SAS and FaDu spheroid models. First, ASS status was assessed in whole cell protein lysates from 2-D and 3-D cultures kept in regular + Arg conditions and upon 2-10 days of Arg deprivation. In spite of different basic ASS protein level in $\mathrm{FaDu}$ and SAS cells, densitometric analysis of WB revealed systematically increasing ASS as function of time throughout mono-ADT for both cell lines in 2-D as well as in 3-D culture (Fig. 6a).

Both FaDu and SAS spheroids stopped growing after transfer into -Arg (Cit supplemented) media but basically remained intact and started to regrow upon re-transfer into $\mathrm{a}+$ Arg environment even after 15 days of starvation in contrast to the more sensitive monolayer cultures (Fig. 6C). The sensitivity loss in the 3-D environment correlates with a less prominent ER stress induction under these conditions (Fig. S4B/C). Monitoring of volume growth kinetics and evaluation of the time to reach the 5-times spheroid volume before treatment $\left(5 \times V_{0}\right)$ relative to + Arg control spheroids allowed to determine a spheroid volume growth delay for each treatment arm and period, respectively. Data reveal that spheroid volume growth was slowed $(\mathrm{FaDu})$ or regrowth was increasingly delayed (SAS with lag phase) with incremental periods of mono-ADT (Fig. 6b/c).

Radioresponse in spheroids was evaluated either by analyzing volume growth delay in case of $100 \%$ spheroid regrowth, i.e. after lower doses of X-rays (Figs. 6b and S4A), or more importantly by monitoring all spheroids over a period of up to 60 days post-treatment, thereby determining the spheroid control probability (SCP) as the proportion of controlled (non-regrown) spheroids as function of time (Fig. 6d/e). The SCP assay used herein allows to determine the analytical endpoint $\mathrm{SCD}_{50}$ (spheroid control dose 50) which is the irradiation dose leading to $50 \%$ of controlled spheroids in analogy to the tumor control probability and $\mathrm{TCD}_{50}$ in vivo assay as highlighted earlier [15]. First signs of controlled spheroids were seen at doses of $15 \mathrm{~Gy}$ and $10 \mathrm{~Gy}$ for SAS and FaDu spheroids, respectively. The $\mathrm{SCD}_{50}$ values were 18.8 Gy for SAS and 13.0 Gy for FaDu spheroids which is in line with the higher intrinsic radioresistance of SAS cells documented earlier in the respective tumor xenograft models [20].

Figure 7a-c clearly document that mono-ADT leads to radiosensitization in HNSCC spheroids and is augmented by comb-ADT. $\mathrm{SCD}_{50}$ values after mono-ADT were significantly lowered relative to + Arg control spheroids (Table S7A/B). In contrast to 2-D culture, slight radiosensitization was also seen in the putative non-responder FaDu model. However, this effect was much smaller than in SAS spheroids and severely impeded-yet not entirely abolished-in the presence of $0.04 \mathrm{mM}$ Cit resulting in mean dose reduction factor (DRF) values of 1.6 for SAS and only 1.1 for FaDu spheroids. Application of $0.1 \mathrm{mM}$ Cav alone appeared to be ineffective showing no radiosensitizing potential; comb-ADT, however, had a clear synergistic impact on radioresponse resulting in $\mathrm{SCD}_{50}$ values as low as 9.6 Gy for SAS and 9.3 Gy for FaDu spheroids. Thus, radiosensitivity was significantly enhanced in SAS and FaDu spheroids upon comb-ADT reflected by mean DRFs of 1.9 and 1.4 , respectively. $\mathrm{SCD}_{50}$ and DRF values with 
A

SAS
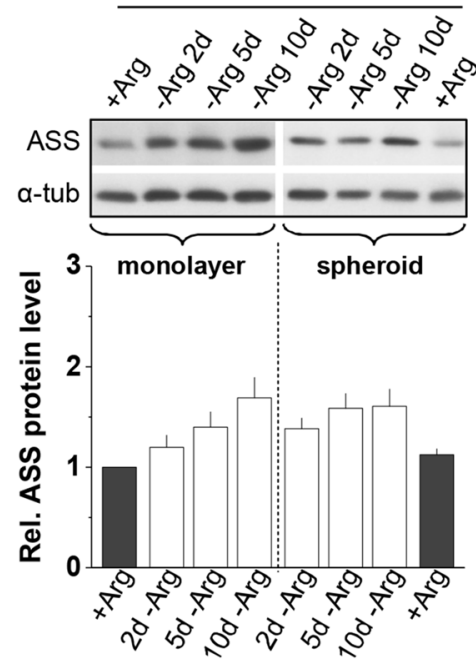

C

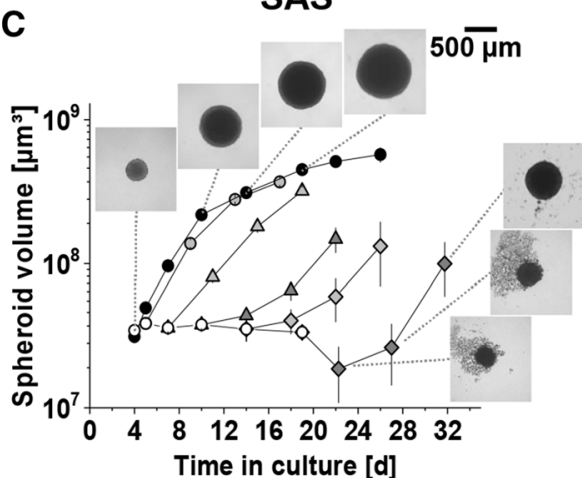

FaDu

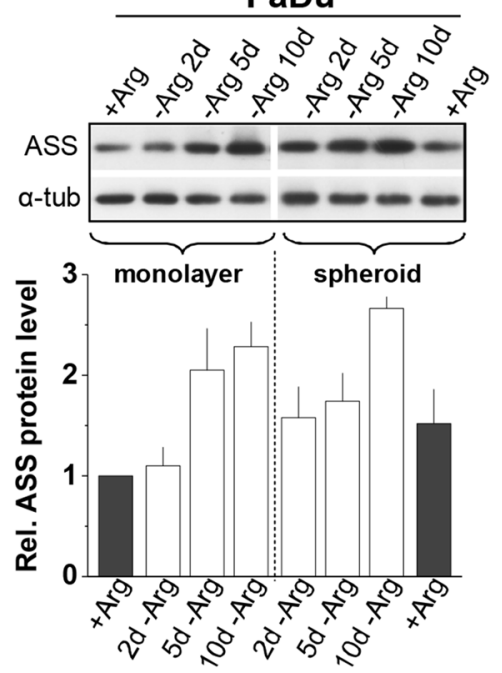

B

3-D volume growth delay [d]

\begin{tabular}{c|cc} 
Treatment & SAS & FaDu \\
\hline ADT & & \\
\hline $1 \mathrm{~d}-\mathrm{Arg}$ & $1.5 \pm 0.3$ & $\sim 0$ \\
3d-Arg & $6.1 \pm 0.6$ & $7.0 \pm 2.8$ \\
$6 \mathrm{~d}-\mathrm{Arg}$ & $13.8 \pm 1.3$ & $12.5 \pm 2.7$ \\
$10 \mathrm{~d}-\mathrm{Arg}$ & $18.8 \pm 2.7$ & $16.7 \pm 3.2$ \\
$15 \mathrm{~d}-\mathrm{Arg}$ & $25.3 \pm 2.0$ & $22.4 . \pm 3.9$ \\
\hline X-ray [Gy] & & \\
\hline 5 & n.d. & $0.4 \pm 1.1$ \\
7.5 & $n . d$. & $6.6 \pm 2.7$ \\
10 & $7.1 \pm 1.3$ & $13.8 \pm 6.5$ \\
12.5 & $11.0 \pm 2.1$ & n.a.
\end{tabular}

n.d. not determined

n.a. not applicable

\section{FaDu}
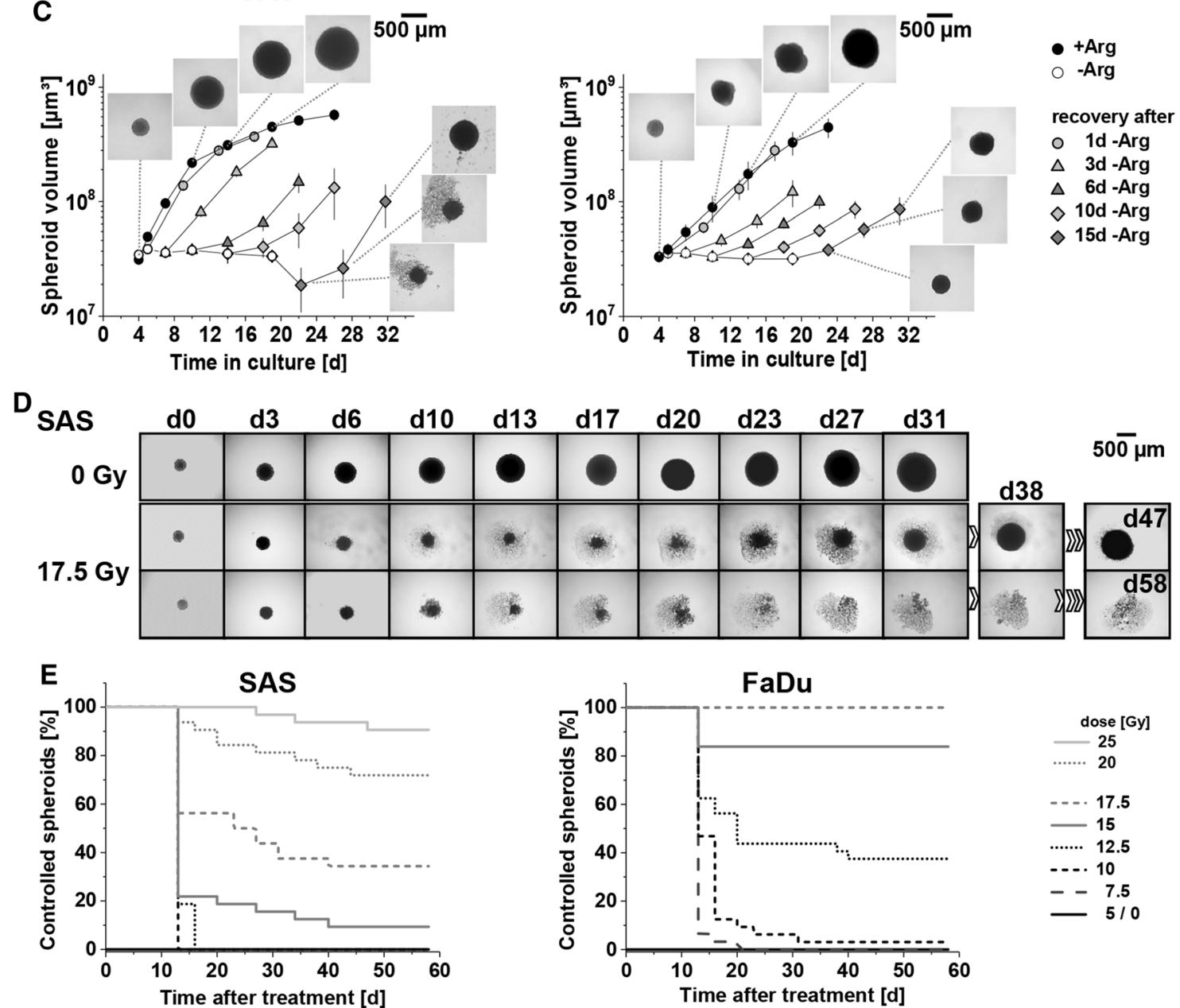

FaDu

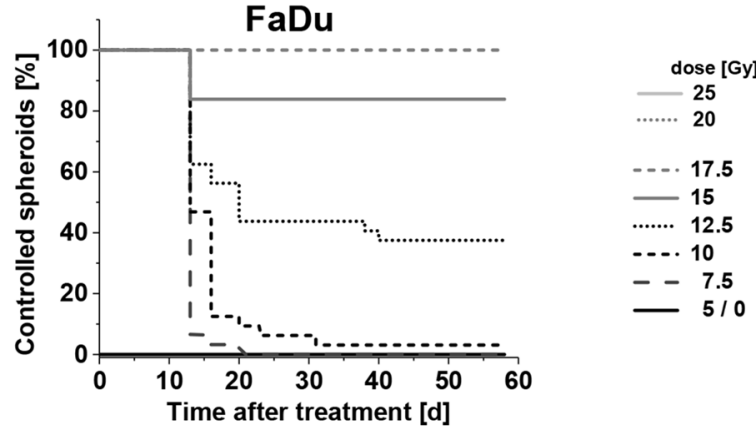


4Fig. 6 HNSCC 3-D cultures are less susceptible to mono-ADT despite an acute growth arrest; 3-D assay well reflects the different radioresponse of SAS and FaDu cells and xenografts (cf. Fig. S2B). a Representative western blots of ASS protein from 2-D and 3-D cultures (SAS, FaDu) grown under - Arg conditions for 2-10 days. Densitometrical analysis of the relative ASS expression normalized to $\alpha$-tubulin are presented as means $( \pm \mathrm{SD})$ from $N=3$ independent experiments. b Volume growth delay (in days) in SAS and FaDu spheroids after different times of Arg-starvation or single dose irradiation with up to 12.5 and $10 \mathrm{~Gy}$, respectively. c Volume growth kinetics of SAS and $\mathrm{FaDu}$ spheroids with and without mono-ADT (1-15 days). After termination of treatment, spheroids were retransferred into standard culture medium to also assess 3-D regrowth capacity and kinetics. $\mathbf{d}$ Image series of representative SAS spheroids without $(0 \mathrm{~Gy})$ and after treatment with $17.5 \mathrm{~Gy}$ single dose X-ray to illustrate readout and analytical endpoint of the spheroid control probability (SCP) assay. A regrown and a controlled spheroid in the treatment arm are shown as examples; the routine monitoring time was 60 days post-treatment. e Proportion of controlled SAS and FaDu spheroids after 5-25 Gy single dose irradiation based on $\geq 30$ spheroids monitored per treatment arm and documented as function of time post-treatment according to $\mathbf{d}$

95\% confidence intervals and statistical evaluation for all treatment arms are listed in Table S7A/B.

\section{Mono-ADT results in analogous and differential metabolic modifications in HNSCC spheroids}

We performed metabolomics profiling to gain first insight into global and differential metabolic alterations induced by mono-ADT in the two HNSCC spheroid models. A targeted GCxGC-MS method [25] allowed us to identify a total of 72 amino-acid-related metabolites in treated and untreated SAS and FaDu spheroids. In brief, we found 11 amino acids including alanine, serine, threonine, leucine and lysine as well as glycerol to be significantly (or tendentially) enhanced upon mono-ADT in both models (Fig. S5B). This is indicative for a general protein and membrane breakdown resulting from Arg deficiency. Alterations in intracellular free amino acids were in most cases more pronounced in the nonresponder FaDu model. Three metabolic features appeared to be differentially affected in the two HNSCC spheroid types, namely urea, phosphoric acid and glutaric acid (Fig. S5C). Urea was reproducibly enhanced only in the treated versus untreated SAS cells while changes in phosphoric acid and glutaric acid levels rather manifested in the FaDu model.

LC-MS-TOF-based untargeted metabolomic profiling was performed to assess global metabolome changes. The respective data documented in Fig. $7 d$ indicate a higher metabolic plasticity in the non-responder FaDu cells with almost 560 metabolic characteristics being critically altered upon mono-ADT, whereas the responder SAS cells showed modifications at a similar significance level only in $<250$ metabolic features. Having said that, the cloud blot also illustrates that different metabolites appear to be affected in the two cell models. The number of metabolites lowered after mono-ADT is proportionally much higher in the responder SAS than in the FaDu cells; the striking depletion of numerous metabolites detected in the retention time period of 5.5-5.8 min which is clearly missing in poor/nonresponder FaDu cells shall be highlighted. The particular treatment-induced increase in metabolome signals at early $(1.2-1.5 \mathrm{~min})$ and very late $(>9 \mathrm{~min})$ retention times in the FaDu model are another, antidromic example (Fig. 7d).

\section{Discussion}

To this day, anti-EGFR treatment with cetuximab has been the only targeted therapy shown to substantially improve HNSCC patient outcome, although its superiority over Cisplatin when combined with irradiation as first-line therapy for locally advanced, non-metastatic HNSCC is increasingly questioned based on recent clinical data [42]. Nonetheless, other molecular targeting approaches have had little success and only cetuximab still remains to be approved by the FDA for multimodal therapy in patients with refractory and/ or metastatic HNSCC and as radiosensitizer in combination with chemoradiation for patients with locally advanced disease [18]. Studies on the potential of metabolic targeting strategies considered for HNSCC patients mainly focus on the identification and development of hypoxia modifiers such as nimorazole, which is in clinical trial as radiosensitizers [43, 44]. Other metabolic targeting approaches such as enzymotherapeutic ADT have not yet been considered in multimodal HNSCC treatment, mainly because of general lack of preclinical data and mechanistic insight for arginine non-auxotrophic cancers.

Although mono-ADT was shown earlier to exhibit some anticancer efficacy in vitro against human laryngeal squamous cell carcinoma cells [45], HNSCC do not belong to the proposed group of Arg-auxotrophic (responding) cancers because the key enzymes for converting Cit to Arg, in particular ASS, are in principle expressed in these tumor cells. Indeed, the ASS1 mRNA levels appears to be significantly upregulated in $\sim 9 \%$ of primary HNSCC and a strong negative correlation between high tumor ASS1 levels and clinical outcome (relapse-free and overall survival) is observed in the HNSCC patient cohort of The Cancer Genome Atlas (TCGA) dataset. According to this data (Fig. S2) and previous findings in oral squamous cell carcinomas [46], the high level of ASS1 seems to be a reliable independent prognostic marker of poor disease-free survival in HNSCC patients. Moreover, our data also revealed a potential intermediate correlation between ASS1 expression level and radioresistance in HNSCC cell lines in vitro. Nonetheless, this observation was not indicative for mono-ADT-induced radiosensitization suggesting that some patients with HNSCC or other aggressive non-auxotrophic cancers might indeed benefit 

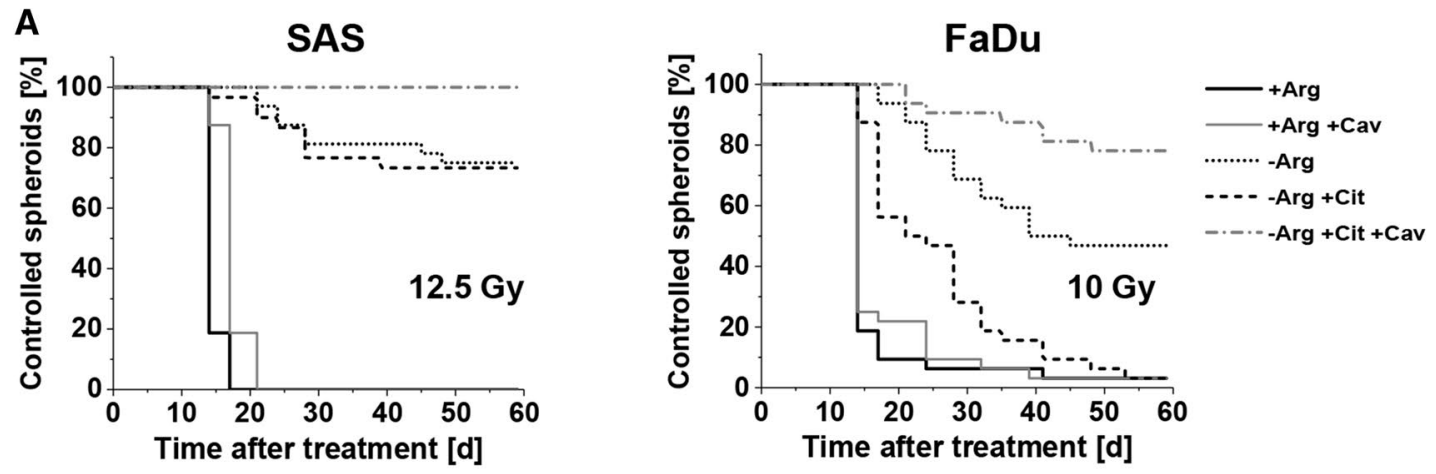

B FaDu $10 \mathrm{~Gy}$

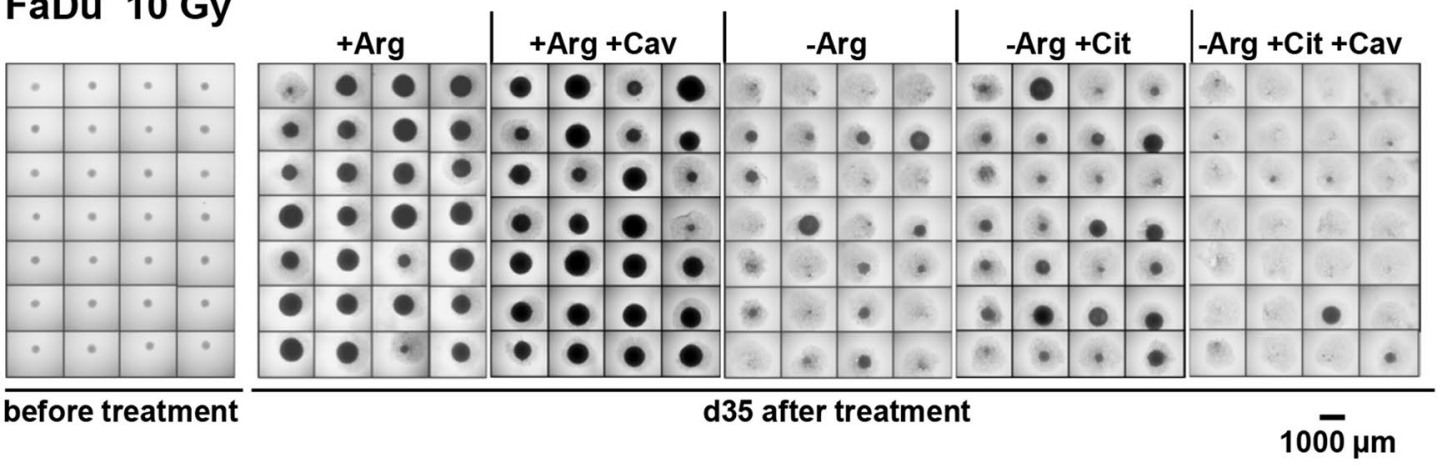

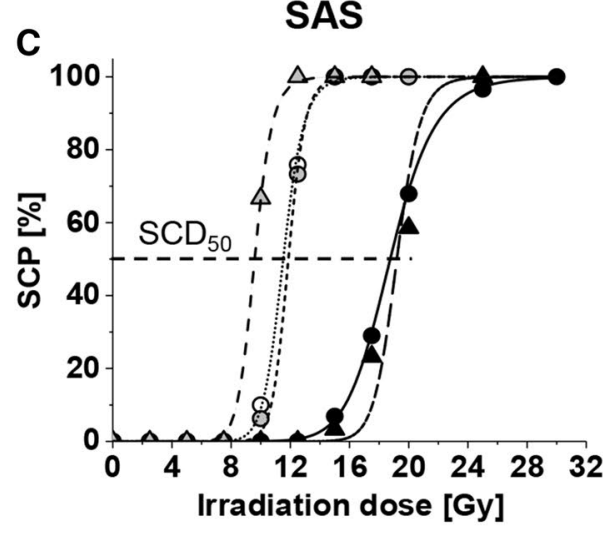

SAS

D 245 features, $p$-value $\leq 0.01$, fold change $\geq 1.5$

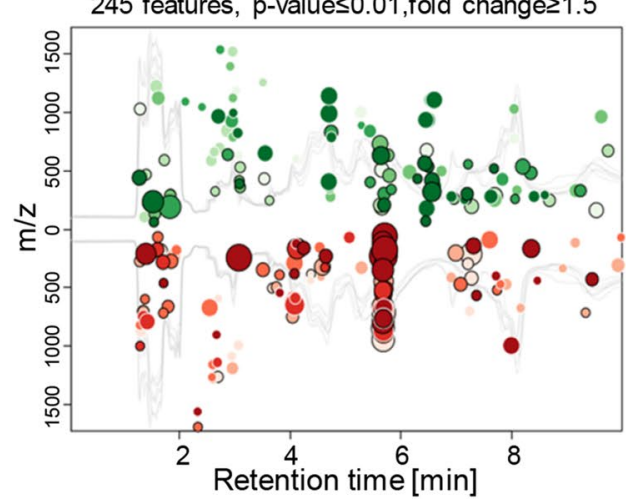

FaDu

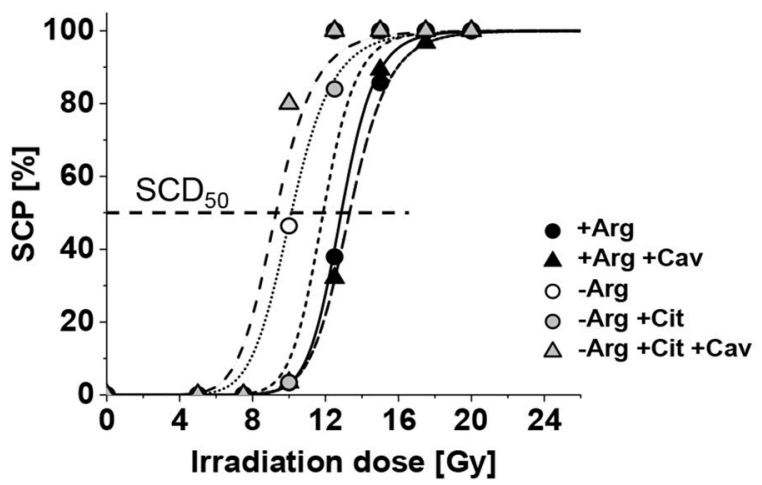

$\mathrm{FaDu}$

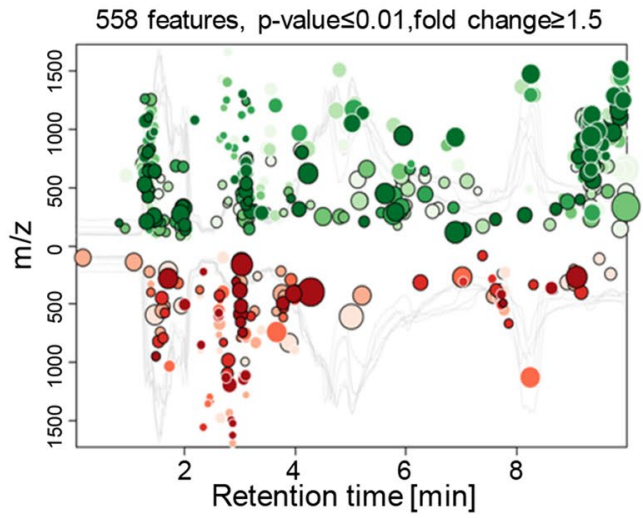


4Fig.7 Mono-ADT mainly radiosensitizes the metabolically less flexible, radioresistant SAS 3-D cultures while comb-ADT evokes a supra-additive radiosensitizing effect in both SAS and FaDu models. In the SCP assays, a minimum of 30 individual spheroids were monitored in each treatment arm over a 60-day post-treatment period (cf. Fig. 5e). a Proportions of controlled spheroids as function of time post-treatment with mono- or comb-ADT (1 day) plus single dose irradiation with 12.5 Gy for more radioresistant SAS spheroids and $10 \mathrm{~Gy}$ for $\mathrm{FaDu}$ spheroids. b Representative images of $\mathrm{FaDu}$ spheroids before and at 35 days post-treatment with comb-ADT and 10 Gy X-ray to illustrate the efficacy of combinatorial treatment. c Spheroid control dose response curves after 0-30 Gy single dose irradiation for spheroids with or without $24 \mathrm{~h}$ pre-exposure to - Arg medium in the absence or presence of $0.04 \mathrm{mM}$ Cit and $0.1 \mathrm{mM} \mathrm{Cav}$. d Interactive cloud plots (generated with the XCMS Online platform) visualizing diverse significantly regulated global metabolic features in SAS and FaDu spheroids upon $24 \mathrm{~h}$ mono-ADT. Color intensities reflect $p$ values and the dot sizes represent the fold change. Plots are produced from $N=2$ independent experiments with up to six technical replicates

from ADT if applied in combinatorial treatment regimes and upon patient stratification.

As expected, the lack of Arg led to a strict growth arrest in all tested HNSCC cells in 2-D culture. However, the exogenous Arg precursor Cit, which is basically present in the blood stream and tissue interstitium, partially promotes growth under-Arg conditions and rescues regrowth capacity in the majority of $\mathrm{HPV}^{-} \mathrm{HNSCC}$ cell lines upon Arg re-supplementation. Indeed, cell-line specific sensitivities to monoADT mainly manifest in differences in re-growth capacity after completion of the treatment and in the response to Cit under Arg-deprived conditions. All HNSCC cell lines express the Arg biosynthetic enzyme ASS and are also positive for ASL. However, neither the expression levels nor the induction of ASS in the absence of Arg correlate with the cells' sensitivity to mono-ADT indicating that the expression of ASS is invalid surrogate marker for treatment response and thus also for patient stratification. Subsequently, we in detail examined whether-and how-prolonged monoADT induces metabolic stress, in particular ER stress, to gain insight into other molecular mechanisms that might determine the cells' response to ADT.

ER stress pathways in mammalian cells are induced by three specific signaling cascades mediated by primary ERlocalized protein stress sensors: IRE1 $\alpha$ (inositol-requiring enzyme 1 alpha), PERK (double-strand RNA-activated protein kinase-like ER kinase), and ATF6 [17, 47, 48]. Upon activation and to restore protein homeostasis, all primary sensors induce signal transduction processes that increase the levels of ER chaperones and inhibit protein entry into the ER by arresting mRNA translation. We found here that mono-ADT triggers a massive and durable ER stress in the more sensitive SAS cells with strong expression of the majority of ER stress response markers, such as IRE1, sXBP1, ATF4, GADD34, CHOP, etc. By contrast, only activation of short-term and mild ER stress upon monoADT was observed in the conditionally resistant $\mathrm{FaDu}$ cells. The most striking differences between responder and non-responder cell models was seen in the activation of the IRE1 $\alpha$-sXBP1 and eIF2 $\alpha$-ATF4-GADD34-(CHOP) pathways as well as their targets. The obtained data suggest that long-term Arg deficiency for yet unknown reasons does not induce massive and acute ER stress in resistant $\mathrm{FaDu}$ cells.

ER stress may induce both pro-survival adaptive and apoptotic responses depending on the severity and durations of the ER stress $[17,48]$. ATF4 and ATF6 regulate CHOP gene expression to trigger apoptosis [35]. These factors as well as apoptosis were induced upon long-term mono-ADT selectively in the responder SAS cell line. However, knockdown of the pro-apoptotic CHOP molecule did not rescue SAS cells from apoptosis, suggesting that the CHOP-mediated pathway most probably is not involved in the mono-ADT-induced ER-stress-related cell death of the responder cells. The same holds true for the IRE1 $\alpha$-XBP1 signaling arm. However, our data clearly reveal that inhibition of GADD34 by Sal or specific siRNA knockdown partially protects SAS cells from mono-ADT-dependent apoptosis. We therefore assume that the profoundly up-regulated GADD34 in SAS cells dephosphorylates eIF2 $\alpha$, abolishes translational inhibition and contributes to further accumulation of unfolded proteins in the ER, thereby also allowing translation of mRNAs encoding pro-apoptotic proteins [32, 33]. In conclusion, ER stress is involved but is not a single player in the multifactorial process contributing to cancer cell death upon mono-ADT.

Cav, a natural Arg proteomimetic analog of plant origin has been shown at low concentration to selectively inhibit proliferation, evokes cell death and eventually sensitize cancer cells to irradiation upon ADT $[9,10,12,13]$. Cav is taken up by cells via the same amino acid transporters as Arg [49]. Its anti-cancer efficacy has been linked to its capability to incorporate into cellular proteins, rendering them misfolded or non-functional thereby inducing ER stress [9, $11,14]$. We demonstrated earlier that the $\mathrm{IC}_{50}$ values of Cav in Arg-free conditions were one order of magnitude lower in various cancer cell lines than in three (pseudo)normal cell types; the latter were also capable of restoring their proliferation upon comb-ADT in contrast to the more sensitive cancer cells [9]. Experiments with a sophisticated 3-D organoid culture of primary human colon epithelium further showed that the combination of an Arg-deprived environment with low dose Cav treatment did not affect normal colonosphere integrity or result in PARP fragmentation as seen in colon cancer cell line organoids [13]. To underline these previous findings, we also applied 3-D cultures originated from various other normal cell types, i.e. normal skin fibroblasts, HUVEC and the retinal pigment epithelial cell line ARPE19. The latter produced discoid aggregates only (Fig. S6A), 
while fibroblast and HUVEC formed more round-shaped non-growing spheroid cultures (Fig. 6b). We found neither Arg-deprivation nor up to $0.1 \mathrm{mM} \mathrm{Cav}$ in the presence or absence of Arg to systematically reduce the viability of any of these cell models in the 3-D environment (Fig. S6). These data further support the hypothesis of a putative therapeutic window for mono- and comb-ADT approaches, although in vivo application will be critical for further evaluation and approval.

In the HNSCC cells, Cav under ADT conditions clearly induced ER stress and apoptosis. Mechanistically, Cav in the absence of Arg evoked a strong activation of the IRE1 $\alpha-$ sXBP1 pathway and of downstream mediators in the eiF2aATF4-GADD34(CHOP) signaling axis. Moreover, the inhibition of GADD34 diminished comb-ADT-induced apoptosis in HNSCC cells, indicating that the two events are linked. Our siRNA-mediated knockdown analyses proved that the IRE1 $\alpha$-SXBP1 pathway as for mono-ADT does not play a significant role in cell death upon comb-ADT. In contrast, GADD34, CHOP and ATF4 molecules turned out to be required for comb-ADT-mediated apoptosis in the responder SAS cells. Thus, Cav at low doses clearly exacerbates the ER stress and pro-apoptotic effects induced by ADT in HNSCC cells.

As the majority of HNSCC patients receive radiotherapy during the course of their disease, we also combined ADT with X-ray irradiation to identify a putative radiosensitizing potential of this treatment option. We are the first to report that more than 50\% of ASS1-positive HPV-negative HNSCC cell lines are indeed radiosensitized by mono-ADT in the presence of physiological Cit concentration. It is known that exposure to ionizing radiation induces ER stress in cancer cells [48, 50, 51]. One of the pathways of ER stress response, the PERK-eIF2 $\alpha$ pathway, was for example shown to modulate radiosensitivity in breast cancer cells $[52,53]$. Moreover, chemical ER stress inducers, such as tunicamycin or thapsigargin, enhanced irradiation-induced caspase 3 activation and DNA fragmentation in intestinal epithelial cells [51]. In the present study, we found the intrinsic radioresistance of SAS cells to be reduced upon ATF4 knockdown indicating an ATF4-dependent pro-survival mechanism in these HNSCC cells. On the other hand, mono-ADT-induced radiosensitization in SAS cells was significantly diminished by the ER-stress modifiers pointing at a causal link between ER stress and radiosensitization. However, the observation that selective siRNA-mediated knockdowns of IRE1, ATF3, CHOP and GADD34 (as well as ATF4) did not modulate the radiosensitizing effect implies a different and even more complex underlying mechanistic scenario as compared to the apoptosis induction by comb-ADT which is clearly mediated in the same cells via the eiF2a-ATF4-GADD34(CHOP) ER stress response signaling pathway.
ATF4 seems to be a pro-survival factor in radioresistant SAS cells, but is also involved in pro-apoptotic signaling when these cells are exposed to ADT in combination with Cav. We, therefore, hypothesized that Cav co-application might switch the ATF4 function resulting in an ADT-synergistic radiosensitizing effect. The latter was indeed proven even in our sophisticated 3-D radioresponse assay when combining ADT with Cav and irradiation. Low doses of Cav clearly enhanced the radiosensitizing potential of ADT in the SAS model and also induced radiosensitization in the initial non-responder FaDu cells both in a 2-D and 3-D environment.

Global metabolic stress and metabolic features of treated HNSCC cells were also recognized in targeted and untargeted metabolomics data. Mono-ADT in general was accompanied by elevated intracellular free amino acids and glycerol as indicators of protein and membrane breakdown. Metabolic modifications seen in both responder and non-responder cells as well as those exclusively related to rhARG-dependent degradation of Arg such as urea accumulation are unlikely to play a role in cell specific radiosensitization as the latter is also seen under dietary-Arg conditions. However, overall the metabolic landscape appeared to be less plastic and more negatively affected by ADT in the responder SAS model which is ultimately more sensitized to combinatorial treatments than the FaDu model. Whether ADT-induced metabolic limitations enhance the susceptibility of SAS cells to irradiation and Cav co-application or the higher metabolic plasticity in the conditionally resistant $\mathrm{FaDu}$ cells reflects particular prosurvival adaptations remains to be elucidated. Yet, the different metabolic dynamics of the two HNSCC models upon treatment suggest complex cellular stress responses beyond the ER.

Notably, other published data suggest that metabolic stress induced by ADT may not only result in autophagy and/or cell death pathways triggered by ER stress response. ADI-PEG20 treatment in prostate cancer cells, for example, critically enhanced ROS generation and impaired mitochondrial function as well as DNA integrity; here, the ROS scavenger $\mathrm{N}$-acetyl cysteine (NAC) could abolish the ADI-PEG -induced effects [54]. A similar response to ADI-PEG20 with respect to ROS generation and mitochondrial dysfunction was reported in ASS1-deficient breast cancer cells [55]. This was revealed in a more recent study showing that Arg is essential for proper mitochondrial respiration and critical for cellular acetyl-CoA level to maintain the $\mathrm{H} 3 \mathrm{~K} 9$ acetylation in the ASS-deficient breast cancer cells [56]. In these cells, ADT reduced glycolytic flux, down-regulated mitochondrial metabolites, inhibited OxPhos via gene regulation, increased ROS production and initiated cell death, while cells lacking mitochondria were resistant to the effects of Arg depletion [56]. ROS are established key modulators in radioresponse 


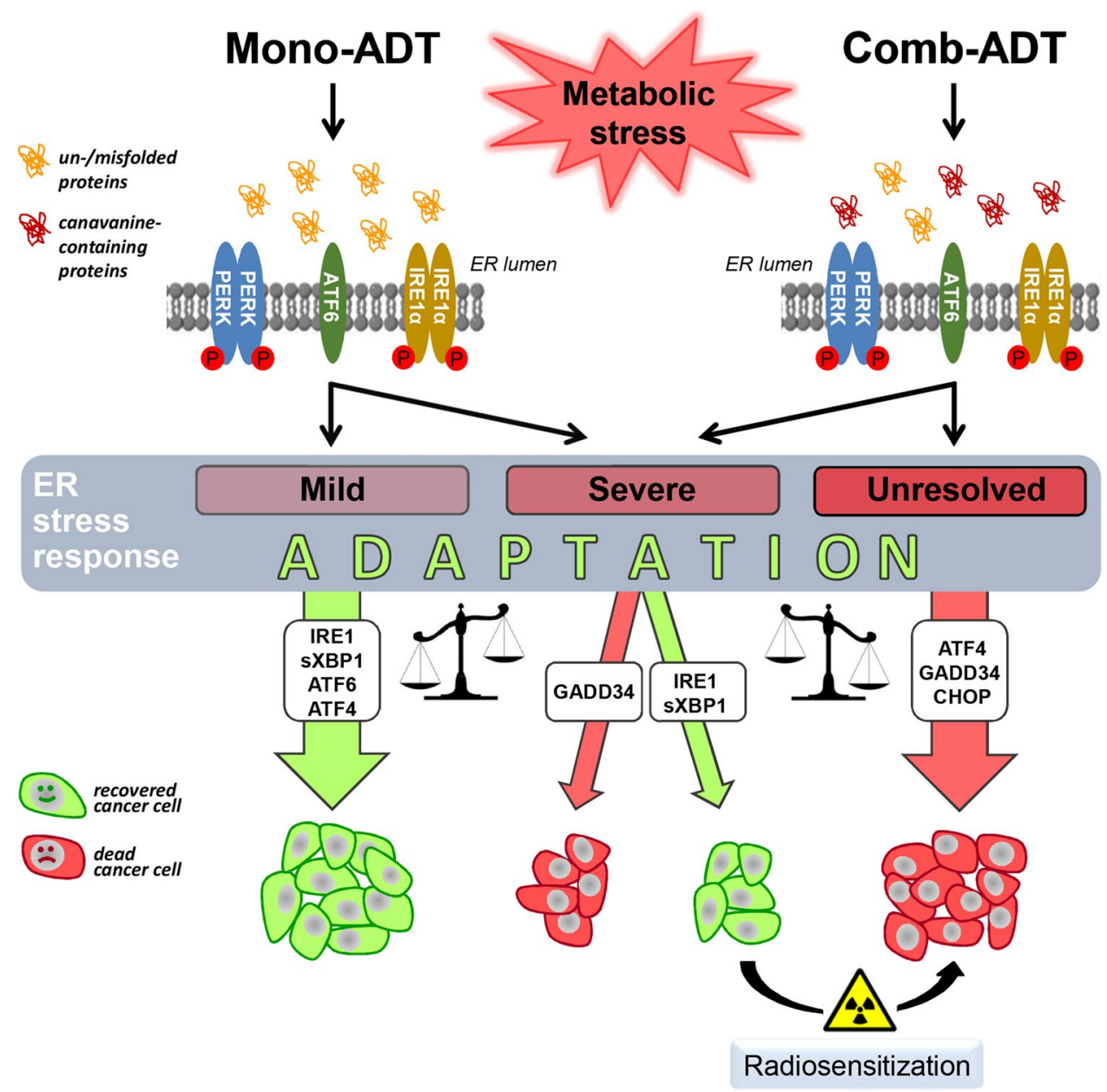

Fig. 8 Schematic illustration of the proposed role of ER stress pathways in mono-ADT and comb-ADT as well as in ADT-induced radiosensitization

(e.g. [57]) and OxPhos inhibition is increasingly recognized in recent years as a strategy to sensitize particular malignant cells to radiotherapy (e.g. [58]), indicating that mitochondrial dysfunction can critically contribute to the radiosensitizing potential of ADT. The relevance of this proposed causal link in ASS1 non-deficient cancers is unclear and shall thus be assessed next in our well-characterized 3-D HNSCC models.

\section{Conclusions}

In summary, the extensive data set of our study implies that ER stress pathways play a dualistic role in the cells' response to ADT depending on their individual intrinsic sensitivity to the triggered ER stress, its severity and duration (Fig. 8). For example, mono-ADT-induced a strong ER stress response only in responsive $\mathrm{SAS}$ cells but not in non-responder $\mathrm{FaDu}$ cells. However, comb-ADT with Cav caused a catastrophic ER stress response and ER stress-mediated apoptosis in both models and elicited a supra-additive effect with respect to radiosensitization. Notably, many natural and synthetic chemical drugs targeting ER stress response pathways are currently under investigation in pre-clinical and clinical trials $[48,59,60]$. Their application to enhance the anticancer efficacy of ADT and improve the curative outcome of radiotherapy is envisioned and should explicitly be explored in vitro and in vivo in parallel to extended mechanistic studies that need to consider the functional analysis of various intracellular organelles including not only ER but also mitochondria. We propose that the combination of ADT with low doses of Cav and/or selective ER stress modulators provides a promising new strategy for radiosensitization of Arg-auxotrophic, but also intrinsically non-auxotrophic cancers such as HNSCC.

Acknowledgements This work was supported by grants from the Free State of Saxony and the European Social Fund (L.A.K.-S., F.M.) and 
by DAAD fellowships (O.C., N.S.). OncoRay has been funded by the BMBF in the program "Center for Innovation Competence". We thank Mrs. Marit Wondrak and Mrs. Melanie Hüther for excellent technical assistance and Mr. Vasyl Lukiyanchuk for useful advice in genetic experiments.

Author contributions OC, OS and LAK-S initiated the study, conceived the project, designed experiments, interpreted results, and wrote the manuscript; OC, LL and FM performed all cell and molecular experimental series; LAK-S, OS, AD and MB supervised the project and provided materials; ZY, BMK and LAK-S planned, performed and interpreted metabolomics analyses; NS and SL assisted with data analysis and statistical evaluation; all authors contributed to the concept of the manuscript.

Funding Open Access funding enabled and organized by Projekt DEAL.

\section{Compliance with ethical standards}

Conflict of interest In the past 5 years, Prof. Michael Baumann attended an advisory board meeting of MERCK KGaA (Darmstadt), for which the TU Dresden received a travel grant. He further received funding for his research projects and for educational grants to the TU Dresden by Teutopharma GmbH (2011-2015), IBA (2016), Bayer AG (2016-2018), Merck KGaA (2016-2030), Medipan GmbH (20142018). For the German Cancer Research Center (DKFZ, Heidelberg) Dr. Baumann is on the supervisory boards of HI-STEM gGmbH (Heidelberg). Dr. Baumann, as former chair of OncoRay (Dresden) and present CEO and Scientific Chair of the German Cancer Research Center (DKFZ, Heidelberg), was or is responsible for collaborations with a multitude of companies and institutions, worldwide. In this capacity, he has signed/signs contracts for his institute(s) and for the staff for research funding and/or collaborations with industry and academia, worldwide. In this role, he was/is further responsible for commercial technology transfer activities of his institute(s), including patent and other similar IP portfolios. Dr. Baumann confirms that none of the above funding sources were involved in the preparation of this paper. Other authors declare no further competing interests.

Open Access This article is licensed under a Creative Commons Attribution 4.0 International License, which permits use, sharing, adaptation, distribution and reproduction in any medium or format, as long as you give appropriate credit to the original author(s) and the source, provide a link to the Creative Commons licence, and indicate if changes were made. The images or other third party material in this article are included in the article's Creative Commons licence, unless indicated otherwise in a credit line to the material. If material is not included in the article's Creative Commons licence and your intended use is not permitted by statutory regulation or exceeds the permitted use, you will need to obtain permission directly from the copyright holder. To view a copy of this licence, visit http://creativecommons.org/licenses/by/4.0/.

\section{References}

1. Stasyk OV, Boretsky YR, Gonchar MV, Sibirny AA (2015) Recombinant arginine-degrading enzymes in metabolic anticancer therapy and bioanalytics. Cell Biol Int 39:246-252

2. Qiu F, Huang J, Sui M (2015) Targeting arginine metabolism pathway to treat arginine-dependent cancers. Cancer Lett 364:1-7
3. Patil M, Bhaumik J, Babykutty S, Banerjee U, Fukumura D (2016) Arginine dependence of tumor cells: targeting a chink in cancer's armor. Oncogene 35:4957-4972

4. Fung MKL, Chan GC (2017) Drug-induced amino acid deprivation as strategy for cancer therapy. J Hematol Oncol 10:144

5. Manig F, Kuhne K, von Neubeck C, Schwarzenbolz U, Yu Z, Kessler BM, Pietzsch J, Kunz-Schughart LA (2017) The why and how of amino acid analytics in cancer diagnostics and therapy. $\mathrm{J}$ Biotechnol 242:30-54

6. Jahani M, Noroznezhad F, Mansouri K (2018) Arginine: challenges and opportunities of this two-faced molecule in cancer therapy. Biomed Pharmacother 102:594-601

7. Feun L, You M, Wu CJ, Kuo MT, Wangpaichitr M, Spector S, Savaraj N (2008) Arginine deprivation as a targeted therapy for cancer. Curr Pharm Des 14:1049-1057

8. Delage B, Fennell DA, Nicholson L, McNeish I, Lemoine NR, Crook T, Szlosarek PW (2010) Arginine deprivation and argininosuccinate synthetase expression in the treatment of cancer. Int J Cancer 126:2762-2772

9. Vynnytska BO, Mayevska OM, Kurlishchuk YV, Bobak YP, Stasyk OV (2011) Canavanine augments proapoptotic effects of arginine deprivation in cultured human cancer cells. Anticancer Drugs 22:148-157

10. Vynnytska-Myronovska B, Bobak Y, Garbe Y, Dittfeld C, Stasyk O, Kunz-Schughart LA (2012) Single amino acid arginine starvation efficiently sensitizes cancer cells to canavanine treatment and irradiation. Int J Cancer 130:2164-2175

11. Bobak Y, Kurlishchuk Y, Vynnytska-Myronovska B, Grydzuk O, Shuvayeva G, Redowicz MJ, Kunz-Schughart LA, Stasyk O (2016) Arginine deprivation induces endoplasmic reticulum stress in human solid cancer cells. Int J Biochem Cell Biol 70:29-38

12. Vovk OI, Chen OI, Igumentseva NI, Senchuk OY, Barska ML, Sybirna NO, Stasyk OV (2016) Effects of the combined arginase and canavanine treatment on leukemic cells in vitro and in vivo. Ukr Biochem J 88:45-55

13. Kurlishchuk Y, Vynnytska-Myronovska B, Grosse-Gehling P, Bobak Y, Manig F, Chen O, Merker SR, Henle T, Löck S, Stange DE et al (2016) Co-application of canavanine and irradiation uncouples anticancer potential of arginine deprivation from citrulline availability. Oncotarget 7:73292-73308

14. Rosenthal GA, Lambert J, Hoffmann D (1989) L-Canavanine incorporation into protein can impair macromolecular function. J Biol Chem 264:9768-9771

15. Hinrichs $C N$, Ingargiola $M$, Käubler $T$, Löck $S$, Temme $A$, Köhn-Luque A, Deutsch A, Vovk O, Stasyk O, Kunz-Schughart LA (2018) Arginine deprivation therapy: putative strategy to eradicate glioblastoma cells by radiosensitization. Mol Cancer Ther 17:393-406

16. Vynnytska-Myronovska BO, Kurlishchuk Y, Chen O, Bobak Y, Dittfeld C, Hüther M, Kunz-Schughart LA, Stasyk OV (2016) Arginine starvation in colorectal carcinoma cells: sensing, impact on translation control and cell cycle distribution. Exp Cell Res 341:67-74

17. Hetz C (2012) The unfolded protein response: controlling cell fate decisions under ER stress and beyond. Nat Rev Mol Cell Biol 13:89-102

18. Cramer JD, Burtness B, Le QT, Ferris RL (2019) The changing therapeutic landscape of head and neck cancer. Nat Rev Clin Oncol 16:669-683

19. Yaromina A, Krause M, Thames H, Rosner A, Krause M, Hessel F, Grenman R, Zips D, Baumann M (2007) Pre-treatment number of clonogenic cells and their radiosensitivity are major determinants of local tumour control after fractionated irradiation. Radiother Oncol 83:304-310 
20. Yaromina A, Thames H, Zhou X, Hering S, Eicheler W, Dörfler A, Leichtner T, Zips D, Baumann M (2010) Radiobiological hypoxia, histological parameters of tumour microenvironment and local tumour control after fractionated irradiation. Radiother Oncol 96:116-122

21. Eicheler W, Zips D, Dörfler A, Grénman R, Baumann M (2002) Splicing mutations in TP53 in human squamous cell carcinoma lines influence immunohistochemical detection. J Histochem Cytochem 50:197-204

22. Friedrich J, Seidel C, Ebner R, Kunz-Schughart LA (2009) Spheroid-based drug screen: considerations and practical approach. Nat Protoc 4:309-324

23. Yoshida H, Matsui T, Yamamoto A, Okada T, Mori K (2001) XBP1 mRNA is induced by ATF6 and spliced by IRE1 in response to ER stress to produce a highly active transcription factor. Cell 107:881-891

24. Ingargiola M, Runge R, Heldt JM, Freudenberg R, Steinbach J, Cordes N, Baumann M, Kotzerke J, Brockhoff G, Kunz-Schughart LA (2014) Potential of a Cetuximab-based radioimmunotherapy combined with external irradiation manifests in a 3-D cell assay. Int J Cancer 135:968-980

25. Yu Z, Huang H, Reim A, Charles PD, Northage A, Jackson D, Parry I, Kessler BM (2017) Optimizing 2D gas chromatography mass spectrometry for robust tissue, serum and urine metabolite profiling. Talanta 165:685-691

26. Tautenhahn R, Patti GJ, Rinehart D, Siuzdak G (2012) XCMS online: a web-based platform to process untargeted metabolomic data. Anal Chem 84:5035-5039

27. Gowda H, Ivanisevic J, Johnson CH, Kurczy ME, Benton HP, Rinehart D, Nguyen T, Ray J, Kuehl J, Arevalo B et al (2014) Interactive XCMS online: simplifying data processing and statistical analyses. Anal Chem 86:6931-6939

28. Kunz-Schughart LA, Schroeder JA, Wondrak M, van Rey F, Lehle K, Hofstaedter F, Wheatley DN (2006) Potential of fibroblasts to regulate the formation of three-dimensional vessel-like structures from endothelial cells in vitro. Am J Physiol Cell Physiol 290:1385-1398

29. Giebe S, Cockcroft N, Hewitt K, Brux M, Hofmann A, Morawietz H, Brunssen C (2017) Cigarette smoke extract counteracts atheroprotective effects of high laminar flow on endothelial function. Redox Biol 12:776-786

30. Gupta T, Kannan S, Ghosh-Laskar S, Agarwal JP (2018) Systematic review and meta-analyses of intensity-modulated radiation therapy versus conventional two dimensional and/or or threedimensional radiotherapy in curative-intent management of head and neck squamous cell carcinoma. PLoS ONE 13:e0200137

31. Pakos-Zebrucka K, Koryga I, Mnich K, Ljujic M, Samali A, Gorman AM (2016) The integrated stress response. EMBO Rep 17:1374-1395

32. Connor JH, Weiser DC, Li S, Hallenbeck JM, Shenolikar S (2001) Growth arrest and DNA damage-inducible protein GADD34 assembles a novel signaling complex containing protein phosphatase 1 and inhibitor 1. Mol Cell Biol 21:6841-6850

33. Novoa I, Zhang Y, Zeng H, Jungreis R, Harding HP, Ron D (2003) Stress-induced gene expression requires programmed recovery from translational repression. EMBO J 22:1180-1187

34. Hiramatsu N, Chiang WC, Kurt TD, Sigurdson CJ, Lin JH (2015) Multiple mechanisms of unfolded protein response-induced cell death. Am J Pathol 185:1800-1808

35. Zinszner H, Kuroda M, Wang X, Batchvarova N, Lightfoot RT, Remotti H, Stevens JL, Ron D (1998) CHOP is implicated in programmed cell death in response to impaired function of the endoplasmic reticulum. Genes Dev 12:982-995

36. Marciniak SJ, Yun CY, Oyadomari S, Novoa I, Zhang Y, Jungreis R, Nagata K, Harding HP, Ron D (2004) CHOP induces death by promoting protein synthesis and oxidation in the stressed endoplasmic reticulum. Genes Dev 18:3066-3077

37. Jiang HY, Wek SA, McGrath BC, Lu D, Hai T, Harding HP, Wang X, Ron D, Cavener DR, Wek RC (2004) Activating transcription factor 3 is integral to the eukaryotic initiation factor 2 kinase stress response. Mol Cell Biol 24:1365-1377

38. Tanaka Y, Nakamura A, Morioka MS, Inoue S, Tamamori-Adachi M, Yamada K, Taketani K, Kawauchi J, Tanaka-Okamoto M, Miyoshi J et al (2011) Systems analysis of ATF3 in stress response and cancer reveals opposing effects on pro-apoptotic genes in p53 pathway. PLoS ONE 6:e26848

39. Boyce M, Bryant KF, Jousse C, Long K, Harding HP, Scheuner D, Kaufman RJ, Ma D, Coen DM, Ron D, Yuan J (2005) A selective inhibitor of eIF2alpha dephosphorylation protects cells from ER stress. Science 307:935-939

40. Hwang SJ, Jeon CJ, Cho SM, Lee GM, Yoon SK (2011) Effect of chemical chaperone addition on production and aggregation of recombinant flag-tagged COMP-angiopoietin 1 in Chinese hamster ovary cells. Biotechnol Prog 27:587-591

41. Vynnytska-Myronovska B, Kurlishchuk Y, Bobak Y, Dittfeld C, Kunz-Schughart LA, Stasyk O (2013) Three-dimensional environment renders cancer cells profoundly less susceptible to a single amino acid starvation. Amino Acids 45:1221-1230

42. Bauml JM, Vinnakota R, Park YH, Bates SE, Fojo T, Aggarwal C, Di Stefano J, Knepley C, Limaye S, Mamtani R et al (2019) Cisplatin versus cetuximab with definitive concurrent radiotherapy for head and neck squamous cell carcinoma: an analysis of veterans health affairs data. Cancer 125:406-415

43. Overgaard $\mathbf{J}$ (2011) Hypoxic modification of radiotherapy in squamous cell carcinoma of the head and neck-a systematic review and meta-analysis. Radiother Oncol 100:22-32

44. Hassan Metwally MA, Ali R, Kuddu M, Shouman T, Strojan P, Iqbal K, Prasad R, Grau C, Overgaard J (2015) IAEA-HypoX. A randomized multicenter study of the hypoxic radiosensitizer nimorazole concomitant with accelerated radiotherapy in head and neck squamous cell carcinoma. Radiother Oncol 116:15-20

45. Lin C, Wang Z, Li L, He Y, Fan J, Liu Z, Zhao S, Ju D (2015) The role of autophagy in the cytotoxicity induced by recombinant human arginase in laryngeal squamous cell carcinoma. Appl Microbiol Biotechnol 99:8487-8494

46. Huang CC, Tsai ST, Kuo CC, Chang JS, Jin YT, Chang JY, Hsiao JR (2012) Arginine deprivation as a new treatment strategy for head and neck cancer. Oral Oncol 48:1227-1235

47. Bravo R, Parra V, Gatica D, Rodriguez AE, Torrealba N, Paredes F, Wang ZV, Zorzano A, Hill JA, Jaimovich E et al (2013) Endoplasmic reticulum and the unfolded protein response: dynamics and metabolic integration. Int Rev Cell Mol Biol 301:215-290

48. Chen OI, Bobak YP, Stasyk OV, Kunz-Schughart LA (2018) A complex scenario and underestimated challenge: the tumor microenvironment, ER stress, and cancer treatment. Curr Med Chem 25:2465-2502

49. Bence AK, Crooks PA (2003) The mechanism of L-canavanine cytotoxicity: arginyl tRNA synthetase as a novel target for anticancer drug discovery. J Enzyme Inhib Med Chem 18:383-394

50. Oommen D, Prise KM (2013) Down-regulation of PERK enhances resistance to ionizing radiation. Biochem Biophys Res Commun 441:31-35

51. Lee ES, Lee HJ, Lee YJ, Jeong JH, Kang S, Lim YB (2014) Chemical chaperones reduce ionizing radiation-induced endoplasmic reticulum stress and cell death in IEC-6 cells. Biochem Biophys Res Commun 450:1005-1009

52. Kim KW, Moretti L, Mitchell LR, Jung DK, Lu B (2010) Endoplasmic reticulum stress mediates radiation-induced autophagy by perk-eIF2alpha in caspase-3/7-deficient cells. Oncogene 29:3241-3251 
53. Nagelkerke A, Bussink J, van der Kogel AJ, Sweep FC, Span PN (2013) The PERK/ATF4/LAMP3-arm of the unfolded protein response affects radioresistance by interfering with the DNA damage response. Radiother Oncol 108:415-421

54. Changou CA, Chen YR, Xing L, Yen Y, Chuang FY, Cheng RH, Bold RJ, Ann DK, Kung HJ (2014) Arginine starvation-associated atypical cellular death involves mitochondrial dysfunction, nuclear DNA leakage, and chromatin autophagy. PNAS 111:14147-14152

55. Qiu F, Chen YR, Liu X, Chu CY, Shen LJ, Xu J, Gaur S, Forman HJ, Zhang H, Zheng S, Yen Y, Huang J, Kung HJ, Ann DK (2014) Arginine starvation impairs mitochondrial respiratory function in ASS1-deficient breast cancer cells. Sci Signal 7:ra31

56. Cheng CT, Qi Y, Wang YC, Chi KK, Chung Y, Ouyang C, Chen YR, Oh ME, Sheng X, Tang Y, Liu YR, Lin HH, Kuo CY, Schones D, Vidal CM, Chu JC, Wang HJ, Chen YH, Miller KM, Chu P, Yen Y, Jiang L, Kung HJ, Ann DK (2018) Arginine starvation kills tumor cells through aspartate exhaustion and mitochondrial dysfunction. Commun Biol 1:178

57. Wang H, Jiang H, Van De Gucht M, De Ridder M (2019) Hypoxic radioresistance: can ROS be the key to overcome it? Cancers (Basel) 11(1):112

58. Ashton TM, McKenna WG, Kunz-Schughart LA, Higgins GS (2018) Oxidative phosphorylation as an emerging target in cancer therapy. Clin Cancer Res 24(11):2482-2490

59. Liu H, Yang J, Li L, Shi W, Yuan X, Wu L (2016) The natural occurring compounds targeting endoplasmic reticulum stress. Evid Based Complement Alternat Med 2016:7831282

60. Ojha R, Amaravadi RK (2017) Targeting the unfolded protein response in cancer. Pharmacol Res 120:258-266

Publisher's Note Springer Nature remains neutral with regard to jurisdictional claims in published maps and institutional affiliations. 